\title{
Evaluation of soil moisture downscaling using a simple thermal-based proxy - the REMEDHUS network (Spain) example
}

\author{
J. Peng ${ }^{1}$, J. Niesel ${ }^{1}$, and A. Loew ${ }^{1,2}$ \\ ${ }^{1}$ Max Planck Institute for Meteorology, 20146 Hamburg, Germany \\ ${ }^{2}$ Department of Geography, University of Munich (LMU), 80333 Munich, Germany \\ Correspondence to: J. Peng (jian.peng@mpimet.mpg.de)
}

Received: 28 July 2015 - Published in Hydrol. Earth Syst. Sci. Discuss.: 31 August 2015

Revised: 20 November 2015 - Accepted: 25 November 2015 - Published: 3 December 2015

\begin{abstract}
Soil moisture retrieved from satellite microwave remote sensing normally has spatial resolution on the order of tens of kilometers, which are too coarse for many regional hydrological applications such as agriculture monitoring and drought prediction. Therefore, various downscaling methods have been proposed to enhance the spatial resolution of satellite soil moisture products. The aim of this study is to investigate the validity and robustness of the simple vegetation temperature condition index (VTCI) downscaling scheme over a dense soil moisture observational network (REMEDHUS) in Spain. First, the optimized VTCI was determined through sensitivity analyses of VTCI to surface temperature, vegetation index, cloud, topography, and land cover heterogeneity, using data from Moderate Resolution Imaging Spectroradiometer (MODIS) and MSG SEVIRI (METEOSAT Second Generation - Spinning Enhanced Visible and Infrared Imager). Then the downscaling scheme was applied to improve the spatial resolution of the European Space Agency's Water Cycle Multi-mission Observation Strategy and Climate Change Initiative (ESA CCI) soil moisture, which is a merged product based on both active and passive microwave observations. The results from direct validation against soil moisture observations, spatial pattern comparison, as well as seasonal and land use analyses show that the downscaling method can significantly improve the spatial details of CCI soil moisture while maintaining the accuracy of CCI soil moisture. The accuracy level is comparable to other downscaling methods that were also validated against the REMEDHUS network. Furthermore, slightly better performance of MSG SEVIRI over MODIS was observed, which suggests the high potential of applying a geostationary satellite for downscaling soil moisture in the future. Overall, con-
\end{abstract}

sidering the simplicity, limited data requirements and comparable accuracy level to other complex methods, the VTCI downscaling method can facilitate relevant hydrological applications that require high spatial and temporal resolution soil moisture.

\section{Introduction}

Soil moisture (SM) is known to be an important state variable that determines the partitioning of surface net energy into latent and sensible heat fluxes, as well as the partitioning of precipitation into infiltration and runoff (e.g., Porporato et al., 2004; Vereecken et al., 2014). In the context of global climate change, accurate information of soil moisture is of great importance for advancing our understanding of the energy and mass exchanges between the atmosphere, hydrosphere, and biosphere (Petropoulos et al., 2015; Seneviratne et al., 2010). In addition, soil moisture is important for numerous practical applications such as irrigation water management (Bastiaanssen et al., 2000), ecological modeling (Nemani et al., 2009), vegetation productivity estimation (Reichstein et al., 2003), and numerical weather prediction (Douville et al., 2000). However, quantifying the spatially and temporally distributed soil moisture properties is still challenging due to dynamic meteorological forcing and surface heterogeneity (Njoku et al., 2003; Loew, 2008). Traditionally, the ground-based measurements of soil moisture are interpolated to a large scale through geostatistical techniques such as kriging (Bárdossy and Lehmann, 1998; Qiu et al., 2001). Such method is however limited to areas where dense soil moisture observational networks are available. 
The advent of satellite remote sensing over the past decades provides an opportunity to obtain soil moisture estimates at global and regional scales without the need of ground-based measurements. Tremendous efforts have been devoted to retrieve soil moisture with measurements from passive and active microwave remote sensing sensors/satellites, including the Advanced Microwave Scanning Radiometer E (AMSR-E) for the Earth observing system, the Advanced Microwave Scanning Radiometer-2 (AMSR2), the Advanced Scatterometer (ASCAT), the Soil Moisture and Ocean Salinity (SMOS), and the recently launched Soil Moisture Active Passive (SMAP) mission. Theoretical and experimental results suggest that both the passive and active sensors are reliable for estimating soil moisture from space (Owe et al., 2008; Petropoulos et al., 2015). The significant advantages of the microwave remote sensing techniques are that (1) dielectric constant measurement can be related directly to soil moisture; (2) soil moisture can be retrieved regardless of the atmospheric conditions (Hain et al., 2011; Loew et al., 2006). To date, several global microwave-based soil moisture products are available, such as the ASCAT soil moisture product (Wagner et al., 1999; Naeimi et al., 2009), the AMSR-E and AMSR2 soil moisture products (Owe et al., 2008; Parinussa et al., 2014a), the SMOS soil moisture product (Kerr et al., 2001; Jacquette et al., 2010), as well as the European Space Agency's Water Cycle Multi-mission Observation Strategy and Climate Change Initiative (ESA CCI) soil moisture product. The CCI SM product is a merged product based on six microwave products (Liu et al., 2011, 2012; Wagner et al., 2012). These soil moisture products normally have a spatial resolution on the order of tens of kilometers, which serves well for global scale applications. However, this spatial resolution is often too coarse for regional and local applications such as agriculture monitoring and drought prediction, which normally require a spatial resolution of $1-10 \mathrm{~km}$ (Crow et al., 2000; Piles et al., 2011).

Optical/thermal infrared (TIR) sensors can provide complementary information of soil moisture patterns at higher spatial resolutions (tens of meters to several kilometers) (Zhang et al., 2014). The surface reflectance observed by optical sensors can be used to explore the state of soil moisture indirectly through empirical spectral vegetation index (Gao et al., 2013; Lobell and Asner, 2002). The common method used by thermal infrared remote sensing to estimate soil moisture is to calculate thermal inertia (Qin et al., 2013; Verstraeten et al., 2006). Yet, the observations from opti$\mathrm{cal} /$ thermal infrared sensors are only available under clearsky conditions. To take the advantages of microwave and optical/TIR remote sensing, more and more studies try to develop synergistic techniques that use multi-sensors to estimate soil moisture at different spatial resolutions. These approaches have a wide range of complexity from empirical regression methods to physically based models (Fang and Lakshmi, 2014; Kim and Hogue, 2012; Merlin et al., 2009; Sahoo et al., 2013). A number of these methods are based on the relationship between land surface temperature (LST) and vegetation index. When the remote sensed surface temperature and vegetation index over heterogeneous areas are plotted, the shape of the scatter plot generally resembles a physically meaningful triangular or trapezoidal feature space, due to different sensitivity of surface temperature to soil moisture variations over bare soil and vegetation covered areas (Carlson et al., 1994; Peng et al., 2013b). Based on this feature space, several indexes such as vegetation temperature condition index (VTCI) (Wan et al., 2004) and temperature vegetation dryness index (TVDI) (Sandholt et al., 2002) have been widely used for assessing the status of soil moisture and monitoring drought conditions (Patel et al., 2008; Karnieli et al., 2010; Mallick et al., 2009; Peng et al., 2013a). Similarly, Chauhan et al. (2003) proposed a soil moisture downscaling scheme that links the soil moisture with surface temperature, vegetation index, and surface albedo through linear regression equation. Following this idea, some other studies have tried to improve the regression models by including other inputs such as brightness temperature and surface emissivity (Piles et al., 2014; Sobrino et al., 2012). Recently, Peng et al. (2016) proposed a new and simple method to improve the spatial resolution of microwave soil moisture with VTCI as the unique downscaling factor. They demonstrated the feasibility of the proposed method via validation against limited ground-based soil moisture measurements and spatial comparison with a land cover map. However, to further investigate the robustness of the proposed method, Peng et al. (2016) suggested that more validation work against dense soil moisture observational networks is required.

Therefore, the present study focuses mainly on investigating the validity and robustness of this simple downscaling scheme through comparison with ground-based soil moisture measurements from a dense observational network (REMEDHUS) in Spain (Martínez-Fernández and Ceballos, 2003). The REMEDHUS site has already been widely used for validation of soil moisture estimates from remote sensing (Brocca et al., 2011; Ceballos et al., 2005; Sánchez et al., 2012). This study has two major objectives. First, it explores and analyzes the sensitivity and robustness of VTCI on LST, vegetation index, clouds, terrain condition, and heterogeneity of land cover and validates the accuracy of soil moisture downscaling using VTCI over the REMEDHUS site. Second, it investigates the merit of using of geostationary satellite data for downscaling soil moisture. Normally the polar orbiting satellites such as Moderate Resolution Imaging Spectroradiometer (MODIS) and Advanced Very High Resolution Radiometer (AVHRR) are in general used for downscaling microwave soil moisture, while the geostationary satellite data are rarely applied. As geostationary observations can provide more cloud-free observations due to their high temporal resolution, they have the potential of estimating the thermal inertia at higher frequencies (Fensholt et al., 2007; Shu et al., 2011; Stisen et al., 2008). Hain et al. (2011) successfully used the Atmosphere-Land Exchange 


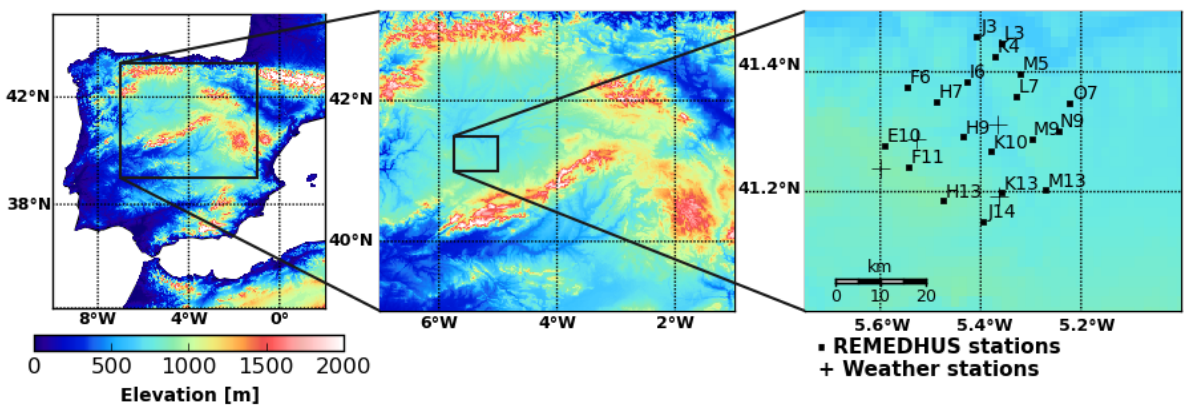

Figure 1. Quick view of the study area in central Spain and the location of the REMEDHUS observation network.

Inverse (ALEXI) model together with thermal infrared observations from geostationary satellites to estimate soil moisture at a relatively high spatial resolution of $3 \mathrm{~km}$. Parinussa et al. (2014b) further inter-compared the geostationary satellite-based soil moisture with microwave-based soil moisture products at various spatial scales over the Iberian Peninsula. They found that all these products agree well with ground-based observations. Thus, the results from both the polar orbit satellite (MODIS Terra/Aqua) as well as geostationary satellite (MSG SEVIRI) were used in the current study to downscale the ESA CCI soil moisture product. To the best of our knowledge, this is also the first study to intercompare the performances of geostationary and orbit satellites for downscaling soil moisture.

\section{Study area and REMEDHUS observation network}

The current study is carried out in Spain, where a central area is selected for downscaling CCI SM due to its relatively flat characteristic (Fig. 1). The land cover of this region is dominated by croplands and shrublands, and the mean elevation of the area is about $650 \mathrm{~m}$ a.s.l. (above sea level). The region has a continental semiarid Mediterranean climate, which is characterized by dry and warm summers and cool to mild and wet winters (Castro et al., 2004; Ceballos et al., 2004). The REMEDHUS soil moisture observation network is in the central part of the study area and shown in Fig. 1 as well. The network covers a $35 \mathrm{~km} \times 35 \mathrm{~km}$ flat area (41.1$41.5^{\circ} \mathrm{N}, 5.1-5.7^{\circ} \mathrm{W}$ ) with elevation ranging from 700 to $900 \mathrm{~m}$ a.s.l. The average annual precipitation and air temperature are $385 \mathrm{~mm}$ and $12^{\circ} \mathrm{C}$, respectively. The land use of the network is mainly rainfed cereals $(78 \%)$, forest and pasture $(13 \%)$, irrigated crops $(5 \%)$, and vineyards $(3 \%)$ (Sánchez et al., 2012). A total of 19 soil moisture stations and 4 automatic weather stations in the REMEDHUS network are used in this study. The soil moisture stations are equipped with capacitance probes that measure top layer (0$5 \mathrm{~cm}$ ) soil moisture at hourly intervals. The details of the 19 soil moisture stations used in our study are summarized in Table 1. The REMEDHUS network has been widely used for different applications such as parameterization of water
Table 1. Descriptions of the 19 soil moisture stations used in the study.

\begin{tabular}{lllll}
\hline Station name & $\begin{array}{l}\text { Short } \\
\text { name }\end{array}$ & Land use & $\begin{array}{l}\text { Elevation } \\
(\mathrm{m})\end{array}$ & $\begin{array}{c}\text { Latitude/ } \\
\left.\text { longitude }{ }^{\circ}\right)\end{array}$ \\
\hline Las Tres Rayas & E10 & Vineyard & 870 & $41.28 /-5.59$ \\
Llanos de la Boveda & L7 & Rainfed & 790 & $41.36 /-5.33$ \\
El Tomillar & H7 & Vineyard & 755 & $41.35 /-5.49$ \\
Las Vacas & O7 & Rainfed & 770 & $41.35 /-5.22$ \\
El Coto & I6 & Vineyard & 720 & $41.38 /-5.43$ \\
Guarena & M13 & Forest-pasture & 720 & $41.20 /-5.27$ \\
Canizal & K13 & Rainfed & 720 & $41.20 /-5.36$ \\
Las Arenas & F6 & Vineyard & 745 & $41.37 /-5.55$ \\
Las Brozas & L3 & Vineyard & 675 & $41.45 /-5.36$ \\
Las Victorias & K4 & Vineyard & 740 & $41.43 /-5.37$ \\
Las Bodegas & H13 & Rainfed & 900 & $41.18 /-5.48$ \\
Casa Periles & M5 & Rainfed & 750 & $41.40 /-5.32$ \\
La Cruz de Elias & M9 & Rainfed & 795 & $41.29 /-5.30$ \\
Concejo del Monte & N9 & Rainfed & 765 & $41.30 /-5.25$ \\
Guarrati & H9 & Forest-pasture & 720 & $41.29 /-5.43$ \\
Paredinas & J3 & Vineyard & 665 & $41.46 /-5.41$ \\
Carretoro & K10 & Rainfed & 745 & $41.27 /-5.38$ \\
La Atalaya & J14 & Rainfed & 830 & $41.15 /-5.40$ \\
Zamarron & F11 & Rainfed & 855 & $41.24 /-5.54$ \\
\hline
\end{tabular}

balance models (Sánchez et al., 2010), calibration and validation of soil moisture products from remote sensing (Sánchez et al., 2012; Wagner et al., 2008), and especially evaluation of downscaled soil moisture products from SMOS and AMSRE (Piles et al., 2014; Sánchez-Ruiz et al., 2014; Zhao and Li, 2013). These studies presented more complex downscaling approaches than the one explored in this study. They provide a baseline to cross compare the downscaling results of this study with their results. Therefore, the study period from 1 January 2010 to 31 December 2011 is chosen to be similar to the published studies and to make the inter-comparison more reasonable. The soil moisture measurements are obtained from the International Soil Moisture Network (ISMN; https://ismn.geo.tuwien.ac.at) (Dorigo et al., 2011, 2013).

\section{Satellite data}

Several satellite platforms with different temporal and spatial resolutions are used in this study. They provide different land surface products such as soil moisture, LST, and vegetation 
indexes. Table 2 gives an overview of these satellite products used in our study.

\subsection{ESA CCI soil moisture}

The ESA CCI soil moisture is a unique multi-decadal (35 years from 1978 to 2013) satellite-based soil moisture data set on a daily basis and at a spatial resolution of $0.25^{\circ}$, which has great potential for climate related studies and applications (Loew et al., 2013). The CCI SM was developed under the framework of ESA Water Cycle Multi-mission Observation Strategy and ESA Soil Moisture Climate Change Initiative (Hollmann et al., 2013). It was generated by merging four passive (Scanning Multichannel Microwave Radiometer (SMMR), Special Sensor Microwave/Imager (SSM/I), Tropical Rainfall Measuring Missions (TRMM) Microwave Imager (TMI), and AMSR-E) and two active (European Remote Sensing Satellite (ERS) Active Microwave Instrument (AMI) and ASCAT) microwave SM products together with a cumulative distribution function (CDF) matching technique. The detailed harmonization procedure is described in Liu et al. $(2011,2012)$. The first version of the CCI SM data set (01.0) was published in 2012 covering the 32-year period from 1978 to 2010 . To extend the temporal coverage to 2013 and improve the gapping filling and processing algorithm, a new version of CCI SM product (02.1) was released recently. It contains three soil moisture products: active only, passive only, and a merged activepassive product. A comprehensive validation of the merged active-passive product using 596 sites from 28 different observation networks worldwide was carried out by Dorigo et al. (2015). It was shown that the CCI SM product has a mean correlation coefficient $(R)$ of 0.46 and an average unbiased root mean square deviation (ubRMSD) of $0.05 \mathrm{~m}^{3} \mathrm{~m}^{-3}$ on daily timescales. Similarly, Albergel et al. (2013) provided an evaluation of CCI SM and two reanalysis soil moisture products using in situ observations from five networks across the world. They concluded that the CCI SM product correlates well with in situ observations with average $R$ of 0.60 . Furthermore, the trend of CCI SM highly agrees with the trends of precipitation and vegetation vigor from various reanalysis products (Albergel et al., 2012; Dorigo et al., 2012; Peng et al., 2015). Therefore, the CCI merged soil moisture is selected in our study to explore the possibility and potential of downscaling to high spatial resolution with optical/thermal infrared data.

\subsection{MODIS land surface temperature and vegetation index}

The MODIS is the primary instrument in the NASA Earth Observing System (EOS) Terra and Aqua satellites, which were launched in December 1999 and May 2002, respectively. With 36 discrete spectral bands ranging from visible to near infrared to thermal infrared, the MODIS has been widely used for land, ocean, and atmosphere research (Salomonson et al., 1989; Huete et al., 2002). The Terra and Aqua satellites have different overpass times of 22:30/10:30 LT for Terra and 01:30/13:30 LT for Aqua in ascending/descending modes. The MODIS data from either Terra or Aqua have been used for downscaling soil moisture (e.g., Srivastava et al., 2013; Choi and Hur, 2012). The surface temperature normally has strong diurnal variation. Therefore, the surface temperature products provided by Terra and Aqua have different values due to the different overpass times of Terra and Aqua. Since surface temperature is one of the most important inputs in downscaling methods, both MODIS/Terra and MODIS/Aqua are used to downscale soil moisture in this study. The MODIS products used in this study are Collection 5 MODIS LST and vegetation indexes (MOD11C1, MYD11C1, MYD11A1 MOD13C1, MCD15A3). Among them, MOD11C1 and MYD11C1 provide daily LST at 0.05 spatial resolution, while MYD11A1 provides daily surface temperature at $1 \mathrm{~km}$ resolution. MOD13C1 contains 16-day composite of normalized difference vegetation index (NDVI) and enhanced vegetation index (EVI). MCD15A3 provides the combined (Terra and Aqua) MODIS leaf area index (LAI) and fraction of photosynthetically active radiation (FPAR) absorbed by vegetation products every 4 days at $1 \mathrm{~km}$ resolution. The above products have all been validated against a wide range of in situ observations, and applied in many scientific studies (Coll et al., 2009; Fensholt et al., 2004; Tian et al., 2002).

\subsection{MSG SEVIRI data}

The Spinning Enhanced Visible and Infrared Imager (SEVIRI) is the main instrument on board Meteosat Second Generation (MSG) geostationary satellites (Schmetz et al., 2002). The SEVIRI has 12 separate channels from visible to thermal infrared and can provide observations at very high temporal resolution (every $15 \mathrm{~min}$ ), which makes it possible to resolve the diurnal cycle of environmental variables such as LST (Peres and DaCamara, 2004). So far, geostationary satellite data have not been used for soil moisture downscaling. Compared to the polar orbit satellites, the geostationary satellites normally provide measurements with relatively low spatial resolution. As for SEVIRI, its spatial resolution is approximately $4.8 \mathrm{~km}$ with spatial sampling of $3 \mathrm{~km}$ for nadir view. But the major advantage of the SEVIRI over MODIS is the high temporal frequency (96 times per day), which can highly increase the possibility of obtaining cloud-free measurements. Furthermore, the downscaling approach used in this study can further benefit from the increased observation frequency through obtaining thermal inertial information from the surface temperature diurnal cycle. The $15 \mathrm{~min} 4.8 \mathrm{~km} \mathrm{LST}$ product generated by the Land Surface Analysis Satellite Applications Facility (LSA-SAF; http://landsaf.meteo.pt) is used in this study. 
Table 2. Descriptions of the satellite-based products used in this study.

\begin{tabular}{lllll}
\hline Satellite product & $\begin{array}{l}\text { Temporal } \\
\text { resolution }\end{array}$ & $\begin{array}{l}\text { Spatial } \\
\text { resolution }\end{array}$ & Projection & Variable used \\
\hline ESA CCI SM & Daily & $0.25^{\circ}$ & - & Soil moisture \\
MOD11C1 (Terra) & Daily & $0.05^{\circ}$ & Plate caree & Surface temperature \\
MYD11C1 (Aqua) & Daily & $0.05^{\circ}$ & Plate caree & Surface temperature \\
MYD11A1 (Aqua) & Daily & $1 \mathrm{~km}$ & Sinusoidal & Surface temperature \\
MOD13C1 (Terra) & 16-day composite & $0.05^{\circ}$ & Plate caree & EVI and NDVI \\
MCD15A3 (Aqua and Terra) & 4-day composite & $1 \mathrm{~km}$ & Sinusoidal & LAI and FPAR \\
LSA-SAF LST & 15 min & $4.8 \mathrm{~km}$ & Curvilinear & Surface temperature \\
\hline
\end{tabular}

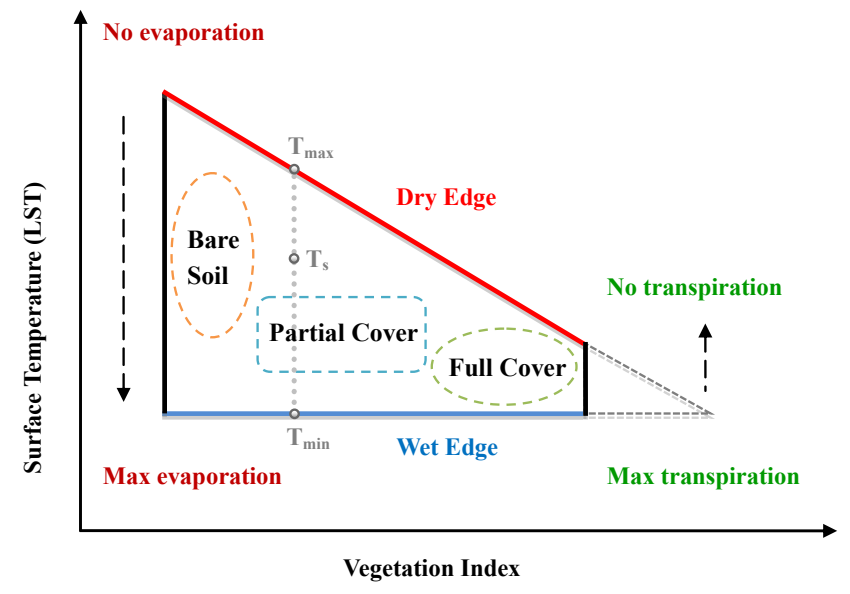

Figure 2. Conceptual diagram of the triangular/trapezoidal feature space that is constructed by land surface temperature and vegetation index.

It should be noted here that the satellite-based products used in this study have different data formats, spatial resolutions, and projections. Therefore, a preprocessing is required to make them consistent in space. The surface temperature and vegetation index products from MODIS and SEVIRI are all resampled to a regular latitude-longitude grid with $0.05^{\circ}$ spacing.

\section{Methodology}

The methodology used in this study includes a soil moisture downscaling scheme and evaluation strategies. The details are described in the following sections.

\subsection{Downscaling scheme}

The soil moisture downscaling scheme used in this study was proposed by Peng et al. (2016). It uses VTCI as the only scaling factor to improve the soil moisture from coarse to high spatial resolution. The theoretical basis of this approach is that the VTCI can represent the status of soil moisture, and has been widely used for estimating soil moisture and moni- toring drought conditions (Petropoulos et al., 2009). The estimation of VTCI is based on the triangular or trapezoidal feature space that is constructed by LST and vegetation index (Fig. 2) over the study area. It is calculated by rescaling the surface temperature of each pixel between two extreme surface temperature values for each vegetation index interval:

$\mathrm{VTCI}=\frac{T_{\max }-T_{\mathrm{s}}}{T_{\max }-T_{\min }}$,

where $T_{\mathrm{s}}$ is the observed surface temperature for a given pixel, $T_{\max }$ and $T_{\min }$ are the corresponding maximum and minimum surface temperatures that have the same vegetation index value as the given pixel. The assumption behind this is that the variation of $T_{\mathrm{s}}$ between the two extreme $T_{\mathrm{s}}$ values reflects the changes of evapotranspiration and soil moisture (Peng and Loew, 2014). The maximum and minimum temperature values form the dry and wet edges in the triangular/trapezoidal feature space. The dry edge reflects the status of limited soil moisture and minimum evapotranspiration, while the wet edge reflects the condition of unlimited soil moisture and maximum evapotranspiration. To accurately estimate dry and wet edges, different approaches have been proposed such as Tang et al. (2010) and Long et al. (2012). Some of these methods are physically based, but increase the operational difficulty due to the requirements of ground-based measurements such as air temperature and wind speed. To keep the simplicity of the downscaling method, we use a relatively simple method proposed by de Tomás et al. (2014) to determine dry and wet edges in this study. The calculation of the dry edge is based on the linear regression between each vegetation index interval and corresponding maximum surface temperatures within this interval ( $T_{\max }=a+b \times$ vegetation index), where $\mathrm{a}$ and $\mathrm{b}$ are the intercept and slope of the dry edge. Before performing the linear fit, the maximum surface temperature that are to the left (with lower vegetation index) and the maximum surface temperature less than mean minimum surface temperature are removed filtering out the spurious dry points and outliers. The wet edge is the mean of the minimum surface temperature within the last five vegetation index intervals. 
In order to downscale the coarse-resolution CCI soil moisture, the spatially average VTCI ( $\overline{\mathrm{VTCI}})$ is then estimated for each CCI soil moisture grid box at $0.25^{\circ}$ (Climate modeling grid - CMG) as

$\overline{\mathrm{VTCI}}=\frac{1}{n} \sum_{i=1}^{n} \mathrm{VTCI}_{i}$,

where $n$ is the number of $0.05^{\circ}$ grids in the $\overline{\mathrm{SM}}, 0.25^{\circ}$ grid. Based on the above results, the following equation is used to downscale the soil moisture:

$\mathrm{SM}=\mathrm{VTCI} \cdot \frac{\overline{\mathrm{SM}}}{\overline{\mathrm{VTCI}}}$,

where $\mathrm{SM}$ is the downscaled CCI soil moisture at $0.05^{\circ}$ (CMG), $\overline{\mathrm{SM}}$ is the actual CCI soil moisture at $0.25^{\circ}$ (CMG), and VTCI stands for the scaling factor at $0.05^{\circ}$ (CMG). Compared to other downscaling methods, this downscaling approach is very simple and requires only limited input data.

Since VTCI is the key variable in the downscaling scheme, it determines the accuracy of the downscaled soil moisture field. The performance of VTCI mainly depends on the accuracy of surface temperature and type of vegetation index. Furthermore, clouds, terrain, and land cover heterogeneity might be also sources of the errors for the estimation of VTCI (de Tomás et al., 2014). Therefore, to optimize the performance of VTCI as the proxy of soil moisture, a sensitivity analysis of VTCI to five influential factors (surface temperature, vegetation index, cloud, topography, and land cover heterogeneity) was conducted before downscaling soil moisture. The VTCI was firstly calculated with different settings (see Table 3). Then the estimated VTCI was compared with ground-based soil moisture measurements from the REMEDHUS network to investigate the influence of the five factors on the performance of VTCI. The details of these factors are listed below, and the combinations of these factors for estimating VTCI are shown in Table 3.

1. Surface temperature: the instantaneous surface temperature observed at the time of satellite overpass is typically used for constructing a triangular/trapezoidal feature space. To avoid the influence of uncertainty of instantaneous surface temperature and make use of thermal inertial information, the surface temperature difference has been used by many studies such as Stisen et al. (2008) and Wang et al. (2006). Therefore, the influence of different surface temperature on the VTCI was investigated using different temperature proxies: (1) daytime temperature from Terra MODIS (10:30 LT), (2) daytime-nighttime temperature difference from Terra MODIS, (3) daytime temperature from Aqua MODIS (01:30LT), (4) daytime-nighttime temperature difference from Aqua MODIS, (5) instantaneous MSG SEVIRI temperature at 10:30 LT, (6) instantaneous MSG SEVIRI temperature at 01:30 LT, (7) MSG

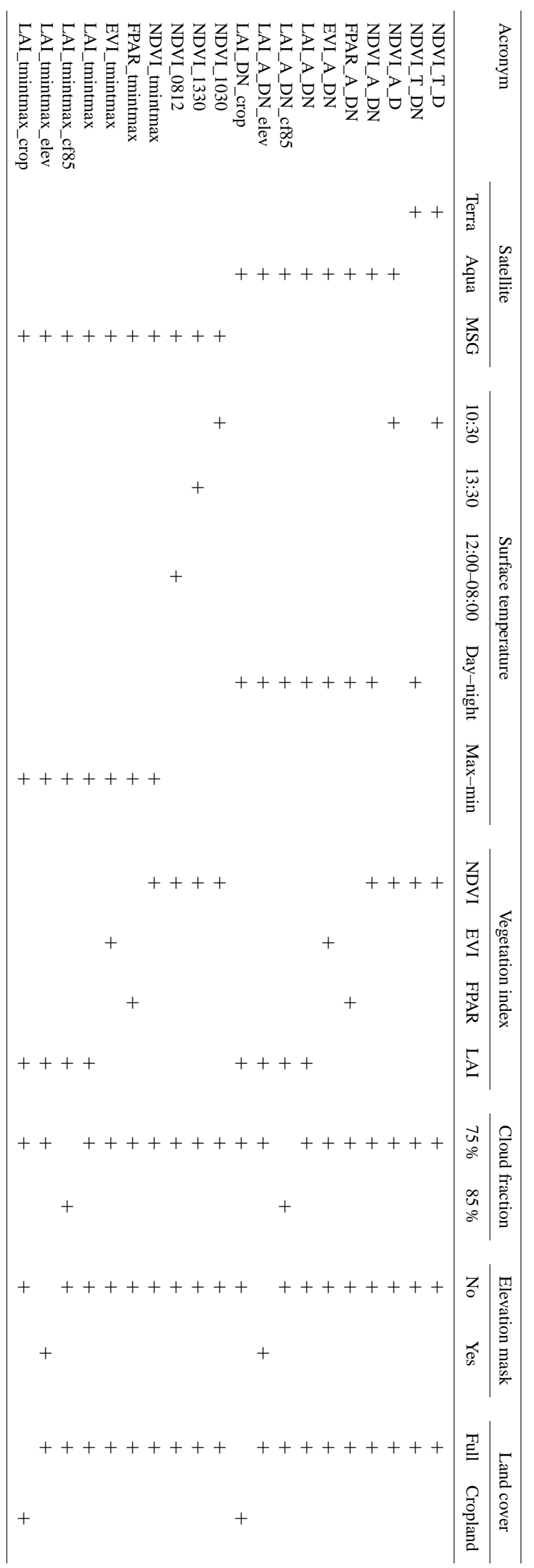

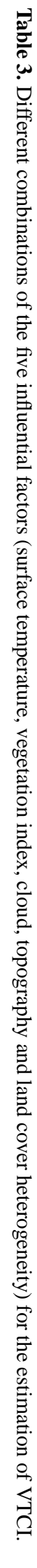


SEVIRI temperature difference between 08:00 and 12:00 LT, and (8) MSG SEVIRI temperature difference between daily maximum and minimum temperature.

2. Vegetation index: the NDVI is originally used for the estimation of VTCI due to its simplicity. But the NDVI can suffer saturation problems at high levels of vegetation density (Carlson et al., 1990). Therefore, different vegetation indexes instead of NDVI such as EVI and LAI are also explored in the present study. To test the impact of different types of vegetation indexes on VTCI, the following vegetation indexes generated by MODIS are investigated: (1) NDVI, (2) EVI, (3) FPAR, and (4) LAI.

3. Cloud: as clouds restrict optical/TIR remote sensing, only measurements under cloud-free conditions are useable. Two cloud thresholds are tested to examine the influence of clouds on VTCI. They are 75 and $85 \%$, which mean that 75 and $85 \%$ of the study area is cloud free. It should be noted here that the higher the threshold is, the fewer clear-sky sample days remain.

4. Topography: the estimation of VTCI requires a relatively flat area, because the variation of surface temperature in the triangular/trapezoidal feature space is assumed to be caused by evaporative cooling effect rather than the variation of elevation. To examine the effects of topography on VTCI, the performances of nonmasked terrain and masked terrain are both tested. In this study the masked terrain is based on removing the areas with $300 \mathrm{~m}$ higher or lower elevation than the average REMEDHUS elevation.

5. Land cover heterogeneity: in order to get the triangular/trapezoidal feature space, the study domain should cover a wide range of soil moisture and vegetation cover conditions. On the other hand, the study area also needs to be homogeneous in terms of vegetation type and surface roughness (Moran et al., 1994). The sensitivity of VTCI to land cover heterogeneity is evaluated at two conditions: (1) full land cover and (2) only cropland.

Finally, the optimized VTCI is calculated based on the sensitivity analysis results. The CCI soil moisture is then downscaled with the optimized VTCI.

\subsection{Evaluation strategies}

Two metrics are used to evaluate the performance of the downscaled soil moisture. The first is a direct comparison between satellite-based products including CCI SM and downscaled CCI SM, and measured soil moisture at each REMEDHUS station. In addition, the cross-comparisons between the present results and reported results from published researches are summarized as well. In order to investigate the influence of land use on the downscaled soil moisture, the comparisons between satellite-based results and in situ measurements are performed per land use of the stations. These land uses are rainfed, vineyard, and forest-pasture. Furthermore, a seasonal analysis is also carried out to examine its influence on downscaled soil moisture. The study period is separated into four seasons to represent different dry/wet conditions and vegetation growth conditions. The four seasons are September-October-November (autumn), DecemberJanuary-February (winter), March-April-May (spring), and June-July-August (summer). The widely used statistical metrics including $R$, mean bias error (BIAS), RMSD, and ubRMSD are used in this study to quantify the differences between satellite-based products and in situ measurements (Entekhabi et al., 2010).

\section{Results and discussion}

\subsection{Sensitivity analyses of the VTCI to surface temperature, vegetation index, cloud, topography, and land cover heterogeneity}

Figure 3 shows the box plots of $R$ for the comparisons between in situ soil moisture measurements and VTCI estimated from different settings (Table 3) for all stations. For the effects of surface temperature, the use of surface temperature difference generally shows better results than the use of instantaneous surface temperature. However, for SEVIRI, the use of temperature difference between 08:00 and 12:00 LT does not improve VTCI compared to the use of instantaneous surface temperature at 10:30 and 1:30 LT. For Terra MODIS, the daytime-nighttime temperature difference method performs slightly worse than the daytime method. As stated before, one advantage of temperature difference method is avoiding the uncertainty of instantaneous surface temperature. The similar performance between the temperature difference method and the instantaneous temperature method can be expected if the surface temperature product has high accuracy. Nevertheless, the improvements of VTCI are clearly observed when using the maximum and minimum temperature difference for SEVIRI, as well as the daytimenighttime temperature difference for Aqua MODIS. These results indicate the effectiveness of integrating the information of thermal inertial. From definition, the thermal inertial requires the maximum diurnal temperature difference, which is fully met by the SEVIRI. For Aqua MODIS, the observations at 13:30 and 01:30 LT are also close to the local maximum and minimum temperature. But in reality, the time of local maximum and minimum temperature change with seasons and locations. Therefore, the use of SEVIRI can give better performance than MODIS platforms due to the better integration of thermal inertial information. It should be also noted that Aqua has slightly better performance than Terra in terms of mean $\mathrm{R}$. The reason is likely because the observation time $(01: 30 / 13: 30 \mathrm{LT})$ of Aqua is closer to the time 

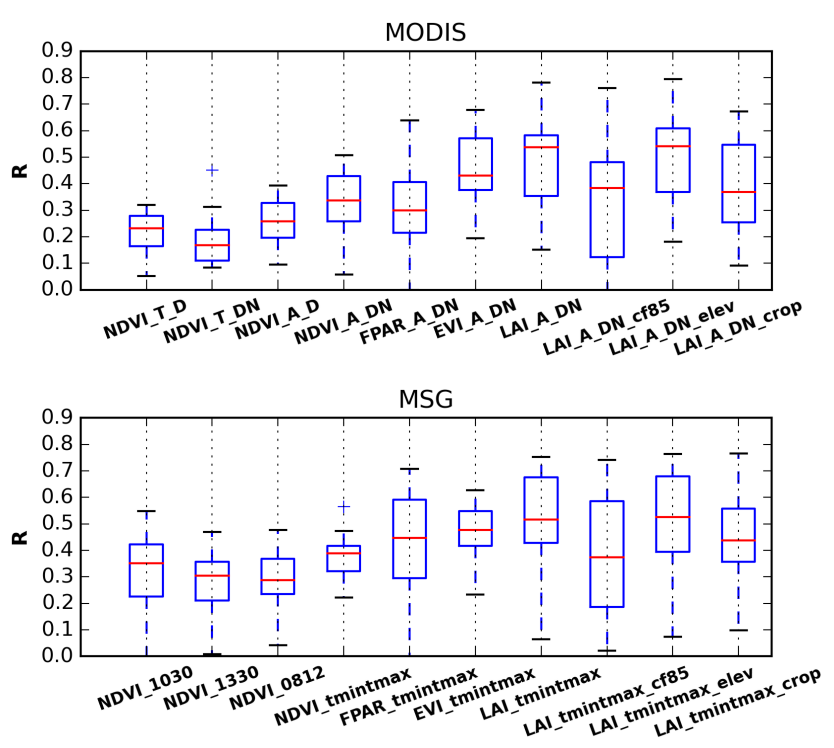

Figure 3. Sensitivity analyses of VTCI to different variables. The box plots show the $R$ values of the comparisons between in situ soil moisture measurements and VTCI calculated from different configurations (Table 3) for all stations. The results for MODIS and SEVIRI are shown separately.

of daily maximum and minimum surface temperature than those of Terra (22:30/10:30 LT).

The change of the VTCI when using different types of vegetation index is also shown in Fig. 3. The LAI gives the best performance in terms of mean $R$ for both SEVIRI and MODIS platforms, and then followed by EVI and FPAR. The NDVI gives relatively worse performance. It is because NDVI is only an indicator of surface greenness due to its sensitivity to effect of soil background. The other indexes are physical parameters and can better represent the reality of vegetation density, which leads to better performance of VTCI. To our knowledge, many studies have used one of these vegetation indexes to form the triangular/trapezoidal feature space, but none of them compare and quantify the difference of VTCI estimated from different types of vegetation indexes. The results suggest that LAI is the best proxy for vegetation cover among different vegetation indexes in the applications based on the triangular/trapezoidal feature space.

Regarding the influence of clouds, Fig. 3 shows that the $85 \%$ cloud mask gives worse performance for VTCI than the $75 \%$ cloud mask. In theory, the increase of the cloud mask threshold should lead to the improvement of the accuracy of VTCI. The opposite result obtained here is due to the sharply decreased sample days for a $85 \%$ cloud mask. It should be noted that the totally clear sky in the study domain is rare in real conditions. The higher cloud mask threshold normally results in less sample days. To keep the balance between avoiding the influence of clouds and having more sample days, we use a $75 \%$ cloud mask in this study.
Contrary to our expectations, the masked terrain performs quite similar to the non-masked terrain method. It is because the masked out pixels are normally located within the triangular/trapezoidal feature space (see green color points in Fig. $5 \mathrm{f}$ and g), which means the dry and wet edges keep almost the same for both methods. Therefore, the terrain has no strong impacts on VTCI in our study area. But for other study areas, the terrain effects still need to be investigated before the estimation of VTCI.

The use of full land cover types gives better performance of the VTCI than the use of croplands. It suggests that although the use of croplands keeps the surface cover more homogeneous in terms of vegetation properties and surface roughness, the range of surface moisture conditions that are required for the estimation of VTCI meanwhile decreases. In arid or semiarid study areas, such as our study area, only one vegetation type cannot represent a wide range of soil moisture that is required by the estimation of VCTI. For these kinds of study areas, the requirements of homogeneous surface cover and wide range of soil moisture conditions cannot be met at the same time. As shown in our results, for the estimation of VTCI, having a wide range of soil moisture is more important than keeping surface cover homogeneous in such areas.

Based on the above results, it can be seen that these factors have strong impacts on performance of VTCI. The optimal configurations in this study for the estimation of VTCI are using Aqua MODIS daytime-nighttime temperature difference, SEVIRI maximum and minimum temperature difference, LAI, $75 \%$ cloud mask, non-masked terrain, and full land cover types.

\subsection{VTCI as a proxy of soil moisture}

To further investigate the performance of VTCI as the proxy of soil moisture, the temporal evolution of station-averaged LAI, surface temperature, VTCI, and in situ soil moisture over REMEDHUS are presented in Fig. 4. Meanwhile, the $R$ between each parameter and soil moisture measurement is also shown. The LAI has a similar seasonal trend as in situ measured soil moisture, but with very low $R$ of 0.04 between them. Compared to LAI, a significantly negative correlation with $R$ of -0.25 ( -0.57$)$ for MODIS (SEVIRI) between surface temperature and soil moisture are obtained. The results suggest that the surface temperature is more sensitive to soil moisture than the LAI. As expected, the VTCI, combining the information from both LAI and surface temperature, agrees well with soil moisture with an $R$ of 0.38 (0.53) for MODIS (SEVIRI), which further demonstrating the effectiveness of VTCI as a proxy of soil moisture.

\subsection{Spatial patterns of the soil moisture estimates}

On the basis of VTCI, the CCI SM is downscaled to high spatial resolution using the proposed method during the study 

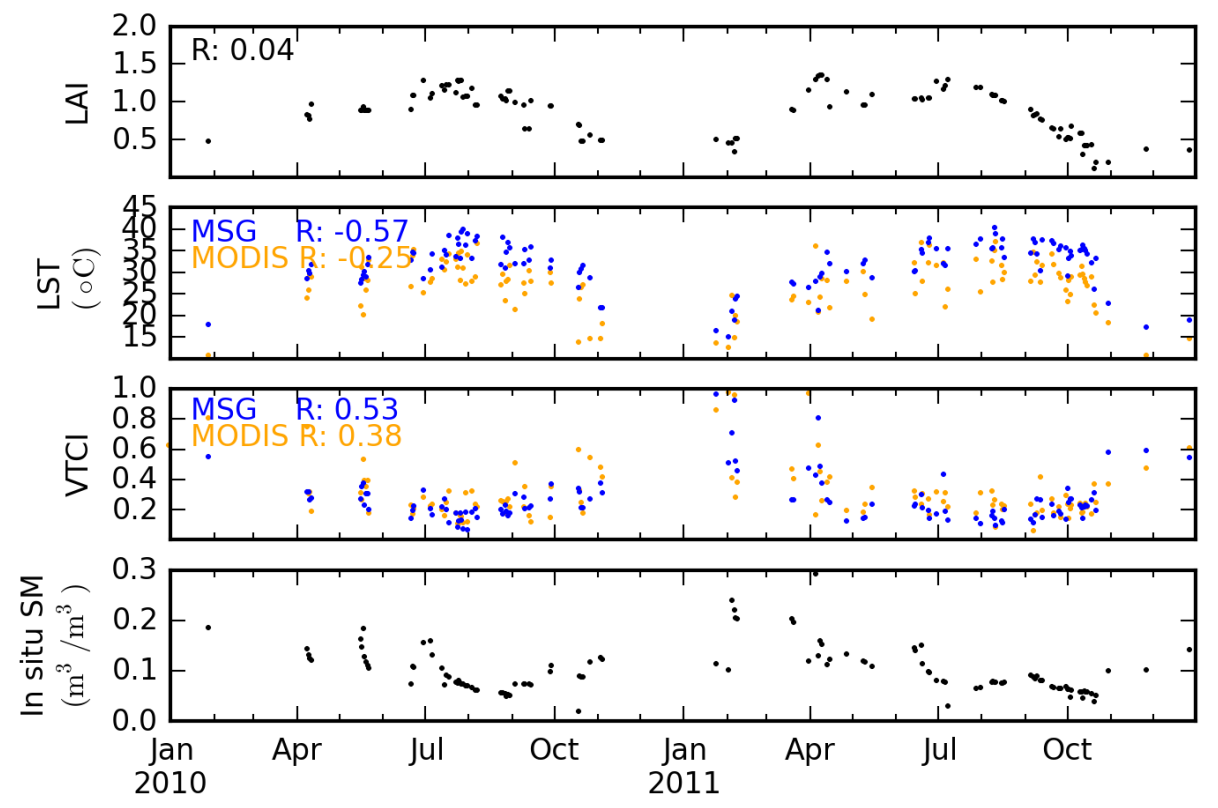

Figure 4. Time series of the station-averaged LAI, surface temperature, VTCI, and in situ soil moisture over REMEDHUS during the study period. The $R$ values listed in the figure refer to the correlation coefficient with measured soil moisture.

time period. The spatial distributions of original CCI SM and downscaled soil moisture on 22 May 2010 are shown in Fig. 5. It can be clearly seen that the downscaled soil moisture (Fig. $5 \mathrm{~b}$ and c) have quite similar spatial patterns as the original CCI SM. High soil moisture is typically presented in northwest and southwest, while low soil moisture appears in northeast and southeast. Meanwhile, the spatial details of the soil moisture are highly improved by the downscaling scheme. The downscaled soil moisture map (Fig. 5d) generated from MODIS also exhibits very similar patterns as that (Fig. 5e) from SEVIRI. It is due to the similar VTCI patterns calculated from MOIDS and SEVIRI. The similar shape of the triangular/trapezoidal feature space constructed from MODIS and SEVIRI can also be seen from Fig. $5 f$ and g. These results suggest that the proposed downscaling scheme can capture the spatial pattern of original CCI soil moisture, and similar performance of downscaled soil moisture maps can be obtained from both MODIS and SEVIRI. The following section will further investigate the accuracy of the downscaled soil moisture and quantify the difference between estimates from MODIS and SEVIRI.

\subsection{Validation of the soil moisture estimates against in situ soil moisture measurements}

The validation results between original CCI SM and in situ soil moisture measurements at each station are shown in Fig. 6, with mean $R$ of $0.53 \pm 0.13$, mean bias of $0.07 \pm 0.08 \mathrm{~m}^{3} \mathrm{~m}^{-3}$, mean RMSD of $0.11 \pm 0.04 \mathrm{~m}^{3} \mathrm{~m}^{-3}$, and mean ubRMSD of $0.05 \pm 0.02 \mathrm{~m}^{3} \mathrm{~m}^{-3}$. These values are consistent with the reported accuracy level of CCI
SM from a recent validation study over Tibetan Plateau (Zeng et al., 2015), and are slightly better than the reported accuracy (mean $R=0.46$, ubRMSD $=0.05 \mathrm{~m}^{3} \mathrm{~m}^{-3}$ ) from the global validation of CCI SM by Dorigo et al. (2015). Regarding the validation results of downscaled soil moisture, the general accuracy level is similar to that of original CCI SM, with mean $R$ of $0.42 \pm 0.17 / 0.48 \pm 0.15$, BIAS of $0.06 \pm 0.09 / 0.06 \pm 0.08 \mathrm{~m}^{3} \mathrm{~m}^{-3}, \quad$ RMSD of $0.12 \pm 0.05 / 011 \pm 0.04 \mathrm{~m}^{3} \mathrm{~m}^{-3}$, and ubRMSD of $0.06 \pm 0.02 / 0.05 \pm 0.02 \mathrm{~m}^{3} \mathrm{~m}^{-3}$ for MODIS and SEVIRI, respectively. When compared to original CCI SM at each individual station, the downscaled soil moisture clearly has a better performance at some stations, such as H9P and M9R, while it performs worse at stations like L3V and K4V. These results suggest that the downscaled soil moisture can maintain the accuracy of original CCI SM but cannot highly improve its accuracy. Similar results have been reported by many soil moisture downscaling studies (Choi and Hur, 2012; Sánchez-Ruiz et al., 2014; Zhao and Li, 2013), which suggest that the accuracy level of downscaled soil moisture highly depend on the original soil moisture. Furthermore, as expected, slightly better performance of SEVIRI over MODIS can be observed due to the better performance of VTCI from MSG, which demonstrates the potential of MSG for downscaling soil moisture.

The temporal variations of downscaled soil moisture for individual station are also investigated here. The stations K13 and M13 are selected due to their representatives of wet and dry soil moisture conditions (Sánchez et al., 2012). Furthermore, the location of K13 is close to one weather station (Fig. 1), which gives us the chance to investigate the con- 


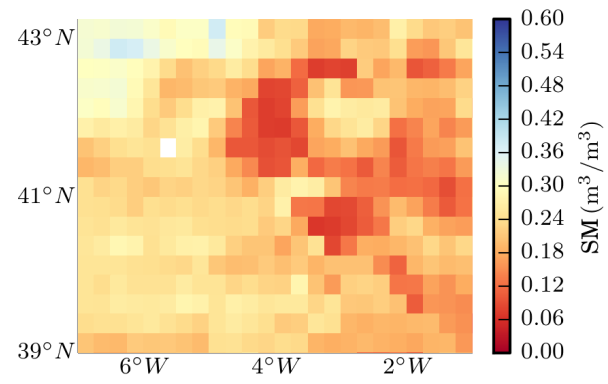

(a) CCI SM

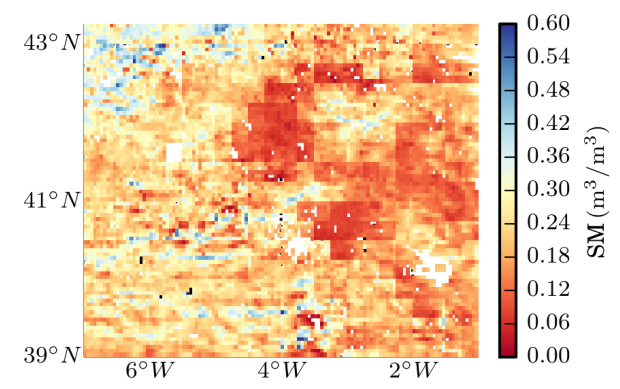

(b) MODIS downscaled SM

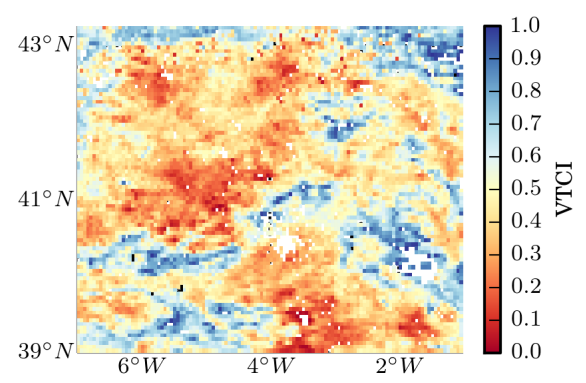

(d) MODIS VTCI

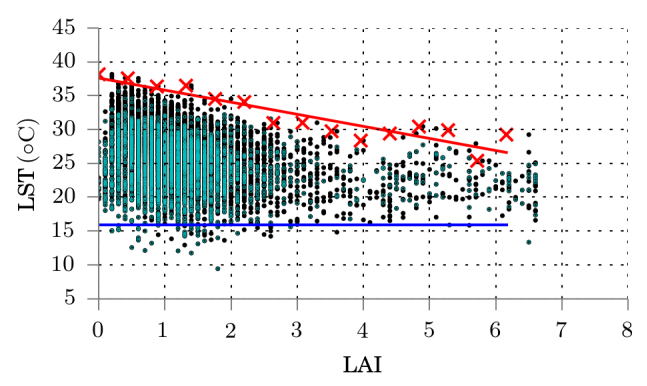

(f) MODIS triangular feature space

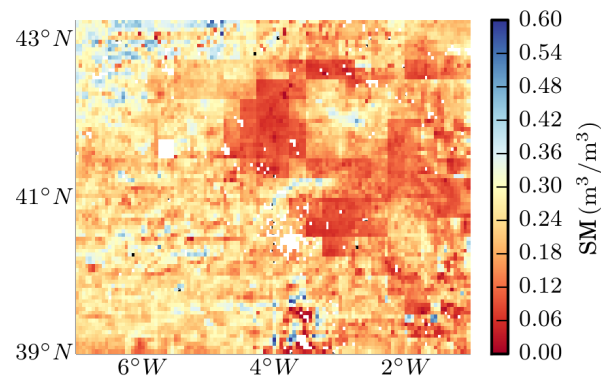

(c) MSG downscaled SM

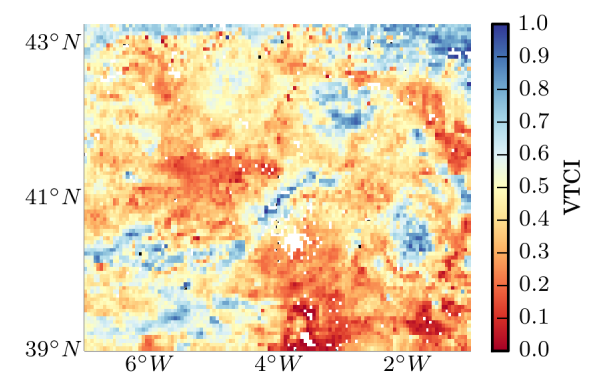

(e) MSG VTCI

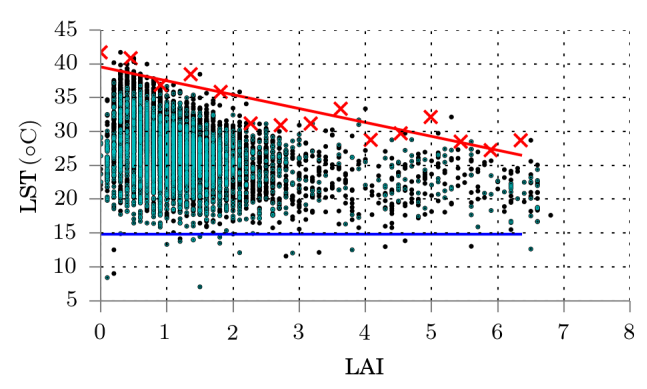

(g) MSG triangular feature space

Figure 5. Spatial comparisons between coarse CCI soil moisture (a) and downscaled CCI soil moisture (b, c) based on MODIS and SEVIRI for 22 May 2010. The corresponding VTCI (d, e) and triangular/trapezoidal feature space (f, g) are also shown. The green points in the triangular feature space indicate the pixels with elevation $300 \mathrm{~m}$ higher or lower than the average REMEDHUS elevation.

nection between soil moisture and rainfall. Figure 7 displays the time series of the in situ soil moisture, CCI soil moisture, downscaled CCI soil moisture, as well as rainfall for stations K13 and M13. For dry station K13, the CCI soil moisture and downscaled soil moisture both agree well with in situ soil moisture. Regarding the wet station M13, the in situ soil moisture responds well to the rainfall, with high soil moisture occurring during the rainfall period in spring. But 


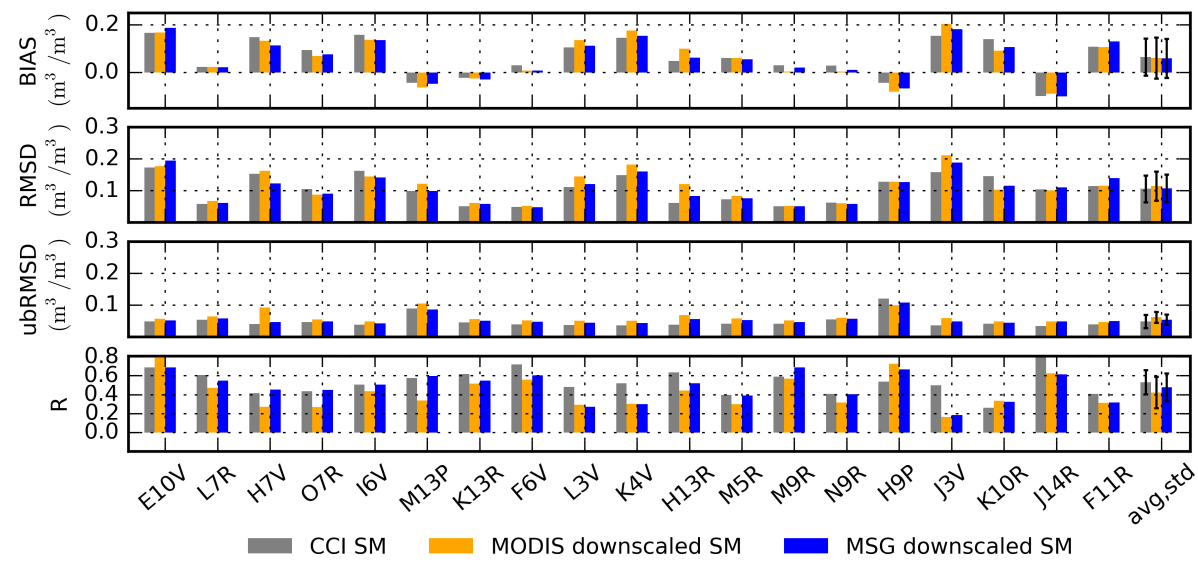

Figure 6. Bar plots for the comparisons between CCI soil moisture, downscaled soil moisture, and in situ soil moisture at each station.

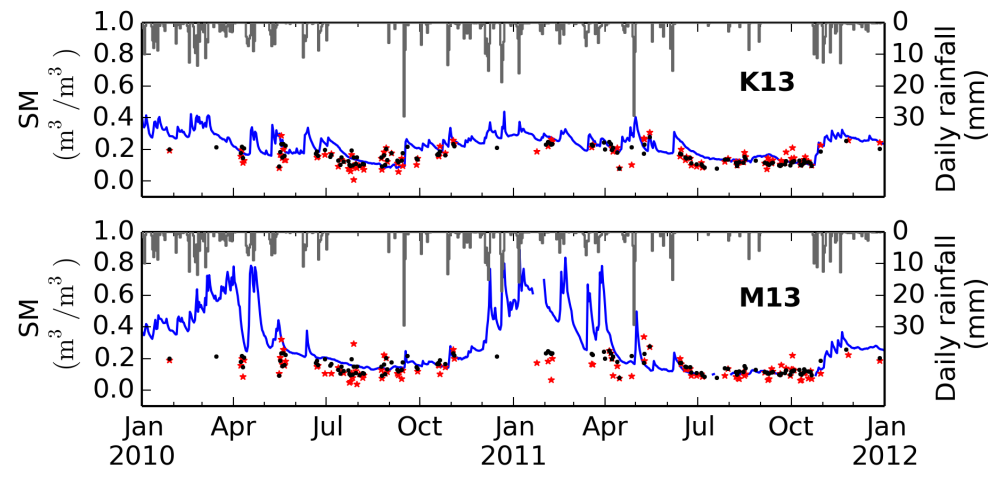

- Measured SM * MODIS downscaled SM . CCI SM
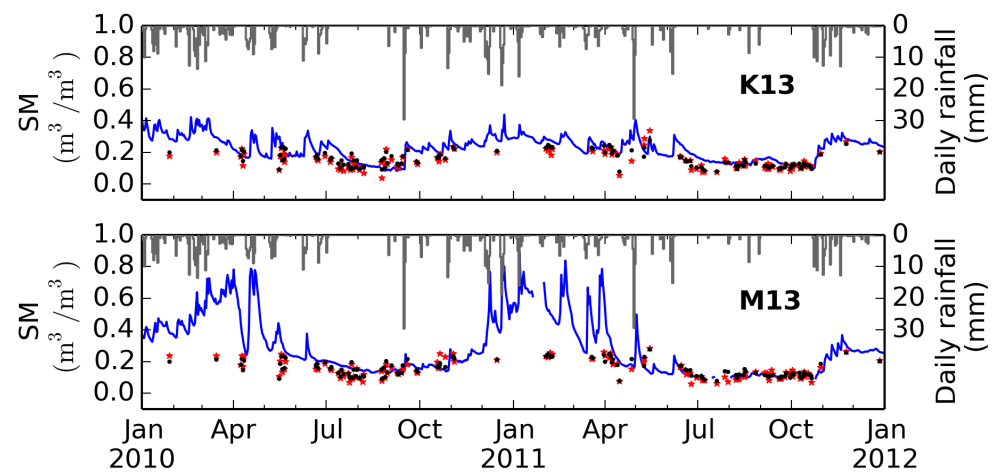

- Measured SM * MSG downscaled SM • CCI SM

Figure 7. Time series of the in situ soil moisture, CCI soil moisture, downscaled CCI soil moisture, as well as rainfall for stations K13 and M13. The results from MODIS and SEVIRI are shown separately.

the CCI soil moisture and downscaled soil moisture seem to be insensitive to the rainfall, presenting a relatively low value compared to in situ soil moisture during the rainfall period. The results here are similar to that reported by Sánchez-Ruiz et al. (2014); i.e., they found that the downscaled SMOS soil moisture has a limited response to rain events.
In addition to the validation at each individual station, the performance of different soil moisture results averaged at the REMEDHUS network scale are also analyzed and summarized in Fig. 8. Similar to the above results, both original CCI SM and downscaled soil moisture agree well with the averaged in situ soil moisture over the network in terms of 
Table 4. Summary of the error statistics from other soil moisture downscaling studies also using REMEDHUS observations for validation. The statistics of the current study are from the comparison of station-averaged soil moisture.

\begin{tabular}{llllrcc}
\hline Reference & $\begin{array}{l}\text { Soil } \\
\text { moisture }\end{array}$ & Sensor & $R$ & $\begin{array}{r}\text { BIAS } \\
\left(\mathrm{m}^{3} \mathrm{~m}^{-3}\right)\end{array}$ & $\begin{array}{r}\text { RMSD } \\
\left(\mathrm{m}^{3} \mathrm{~m}^{-3}\right)\end{array}$ & $\begin{array}{c}\text { ubRMSD } \\
\left(\mathrm{m}^{3} \mathrm{~m}^{-3}\right)\end{array}$ \\
\hline Sánchez-Ruiz et al. (2014) & SMOS & MODIS & 0.73 & -0.026 & 0.049 & 0.042 \\
Piles et al. (2014) & SMOS & MODIS & 0.590 & -0.010 & 0.050 & 0.040 \\
Zhao and Li (2013) & AMSR-E & SEVIRI & 0.467 & 0.108 & 0.109 & - \\
Current study & CCI SM & MODIS & 0.580 & 0.063 & 0.076 & 0.042 \\
& & SEVIRI & 0.617 & 0.060 & 0.072 & 0.040 \\
\hline
\end{tabular}

$R$, BIAS, RMSD, and ubRMSD. But systematic overestimation of soil moisture from all of them can also be observed. It implies that the CCI SM has the problem of overestimating soil moisture, which needs to be further investigated. Overall, the above results suggest that the downscaled soil moisture can preserve the accuracy of coarse CCI SM, and meanwhile present more detailed spatial details. Since the proposed downscaling method highly depends on the original CCI soil moisture and VTCI, the accuracy of the downscaled soil moisture is expected to be improved if the VTCI can better represent the soil moisture.

Furthermore, the above results are also compared with other published soil moisture downscaling studies. These studies apply different downscaling methods to downscale soil moisture product from SMOS and AMSR-E, using either MODIS or SEVIRI data as inputs. The results are all validated against the observations from the REMEDHUS network, which makes them ideal for inter-comparison with our results. Table 4 lists the statistics of the comparison between downscaled and measured soil moisture from different studies. It can be seen that the $R$, BIAS, RMSD, and ubRMSD of these published studies range, respectively, from 0.467 to $0.73,-0.026$ to $0.108 \mathrm{~m}^{3} \mathrm{~m}^{-3}, 0.049$ to $0.109 \mathrm{~m}^{3} \mathrm{~m}^{-3}$, and 0.040 to $0.042 \mathrm{~m}^{3} \mathrm{~m}^{-3}$. The corresponding statistics of the current study are within theses ranges, which imply that the results of current study are reasonable and satisfactory. Considering the simplicity, limited inputs, and acceptable accuracy, we conclude that the proposed downscaling method is feasible and effective for improving soil moisture from coarse to high spatial resolution.

\subsection{Seasonal and land use analyses of the soil moisture estimates}

To investigate the performance of the downscaling method over different climatic and vegetation growth conditions, seasonal analysis has been performed based on the comparisons between network-averaged soil moisture estimates and in situ soil moisture observations for different seasons. Figure 9 shows the statistical results of the comparisons between CCI SM, downscaled soil moisture, and in situ soil moisture. It can be seen that the downscaled soil moisture especially from SEVIRI has a similar performance to the original CCI SM,

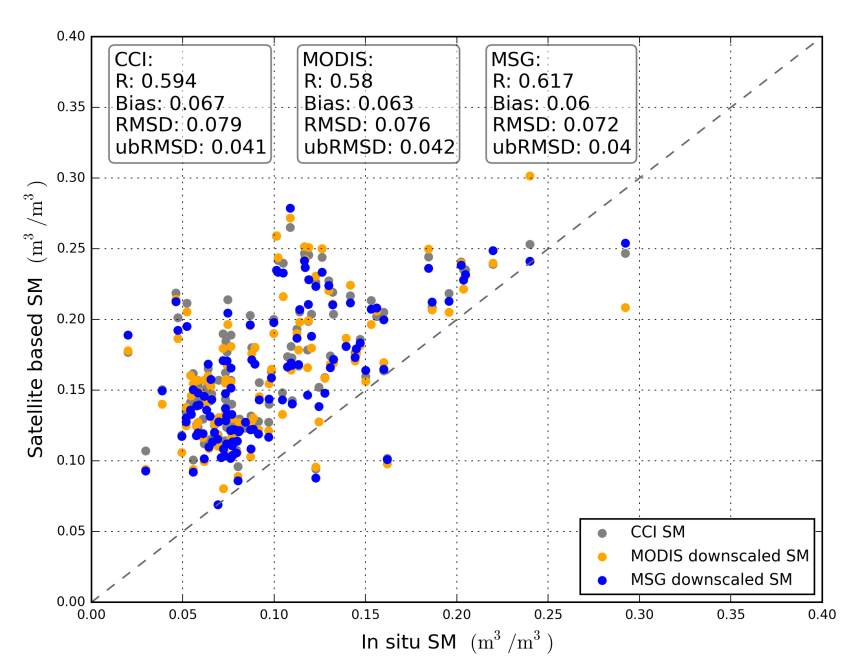

Figure 8. Scatter plots of the REMEDHUS network-averaged estimates and soil moisture measurements. The corresponding comparison statistics are shown as well.

with better performance in summer and winter in terms of $R$, BIAS, RMSD, and ubRMSD values. The worse performance in spring might be due to flat temporal pattern of CCI SM (Fig. 7). As discussed in Sect. 5.4, it seems that CCI SM has limited response to rainfall, while the study area has frequent rainfall during spring. Compared to CCI soil moisture, the downscaled soil moisture from SEVIRI has a slightly better performance in terms of $R$ and BIAS. Similar to the previous results, the SEVIRI generally has slightly better performance than MODIS in terms of $R$, BIAS, RMSD, and ubRMSD values.

The influence of land use on the downscaling scheme is also investigated and the results are summarized in Fig. 10. The stations are divided into three land use groups: vineyard (7), rainfed (9) and forest-pasture (2). Figure 10 shows the performances of original CCI SM and downscaled SM over different land use categories. It can be seen that vineyard and rainfed have a similar performance in terms of $R$ and ubRMSD, while the forest-pasture presents relatively high $R$ and ubRMSD that might be due to its limited number of stations. These results suggest that both CCI SM and downscaled soil moisture are not sensitive to the generally used 

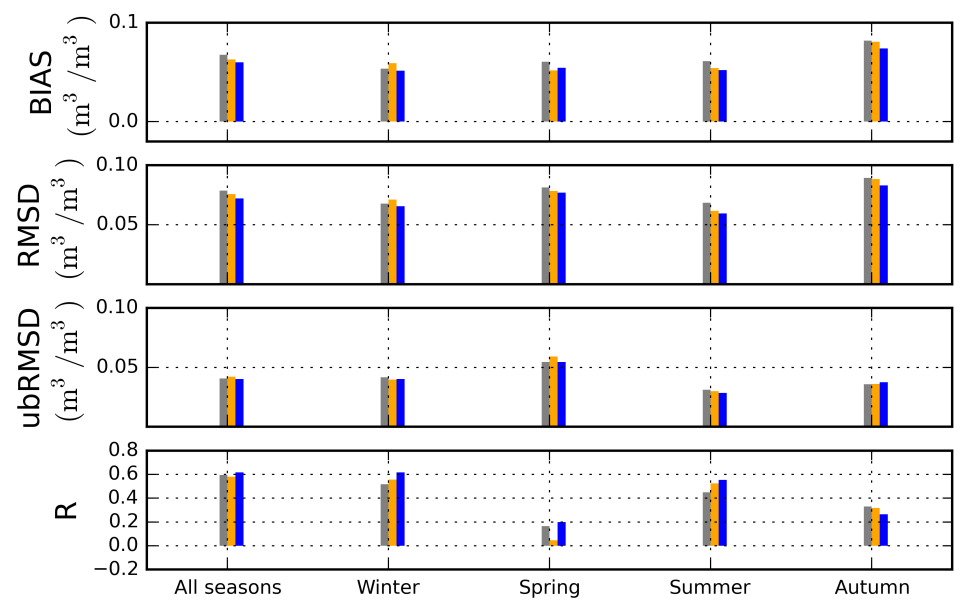

\section{SM MODIS downscaled SM}

MSG downscaled SM

Figure 9. Bar plots for the comparisons between soils moisture estimates and in situ soil moisture over seasons.
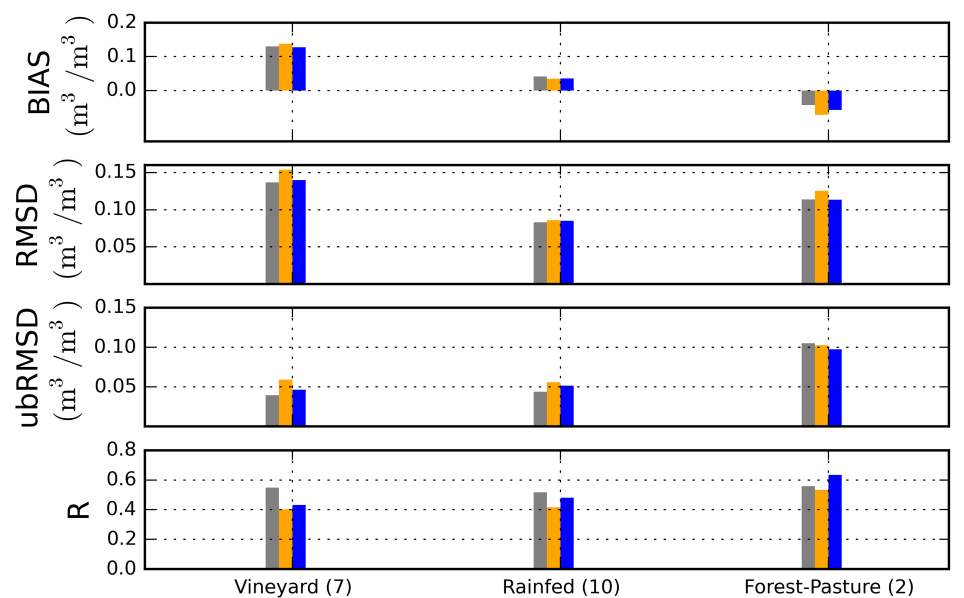

$\mathrm{CCI} \mathrm{SM}$

MODIS downscaled SM

MSG downscaled SM

Figure 10. Bar plots for the comparisons between soils moisture estimates and in situ soil moisture per land use (vineyard, rainfed, and forest-pasture).

land use. Furthermore, the results from MODIS and SEVIRI have a similar performance, which further implies that the proposed method is independent on platforms. It has the potential to be used on different platforms and other regions.

\subsection{Evaluation of downscaled soil moisture at different spatial resolutions}

Since MODIS has the advantage of providing measurements at high spatial resolution of $1 \mathrm{~km}$, it gives us the opportunity to evaluate the downscaled soil moisture at different spatial resolutions. Figure 11 displays the spatial patterns of downscaled soil moisture at $1 \mathrm{~km}$ and $0.05^{\circ}$ (CMG) on 22 May 2010. It can be seen that these two maps have quite similar patterns, implying that the downscaling scheme can be applied at different spatial scales. To further evaluate the performance of downscaled soil moisture at different spatial resolutions, Fig. 12 shows the bar plots of the comparisons between downscaled soil moisture from MODIS different spatial resolution MODIS and measured soil moisture at each station. In general, the downscaled soil moisture at $1 \mathrm{~km}$ has similar accuracy level as that at $0.05^{\circ}$, which suggests that the accuracy of CCI soil moisture can be preserved at higher spatial resolutions. Besides, the $1 \mathrm{~km}$ soil moisture has a slightly better performance than $0.05^{\circ}$ soil moisture in terms of mean $R(0.465 / 0.44)$, RMSD $\left(0.112 / 0.113 \mathrm{~m}^{3} \mathrm{~m}^{-3}\right)$, and ubRMSD $\left(0.055 / 0.058 \mathrm{~m}^{3} \mathrm{~m}^{-3}\right)$ values. It further sug- 


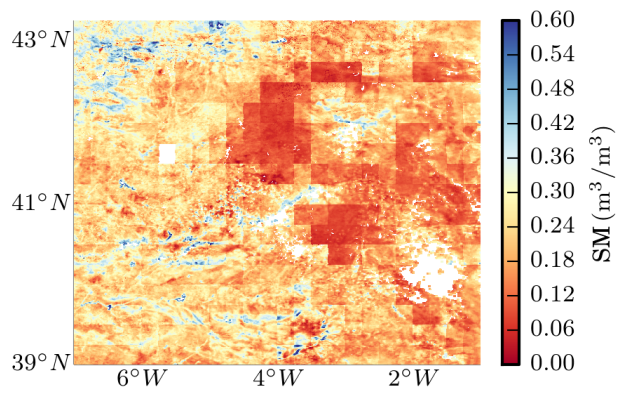

(a) MODIS downscaled SM $(1 \mathrm{~km})$

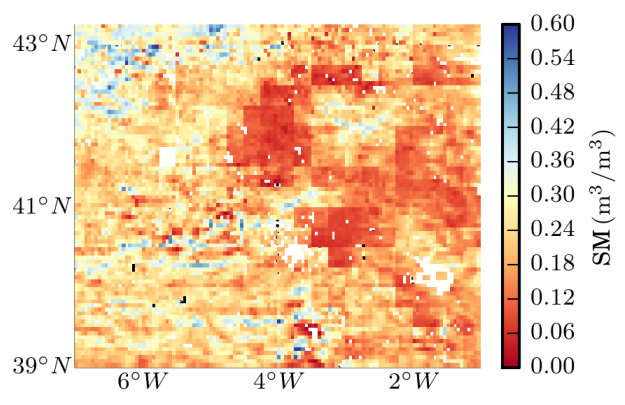

(b) MODIS downscaled SM $\left(0.05^{\circ}\right)$

Figure 11. Spatial patterns of the downscaled soil moisture from MODIS at (a) $1 \mathrm{~km}$ and (b) $0.05^{\circ}$ spatial resolutions.

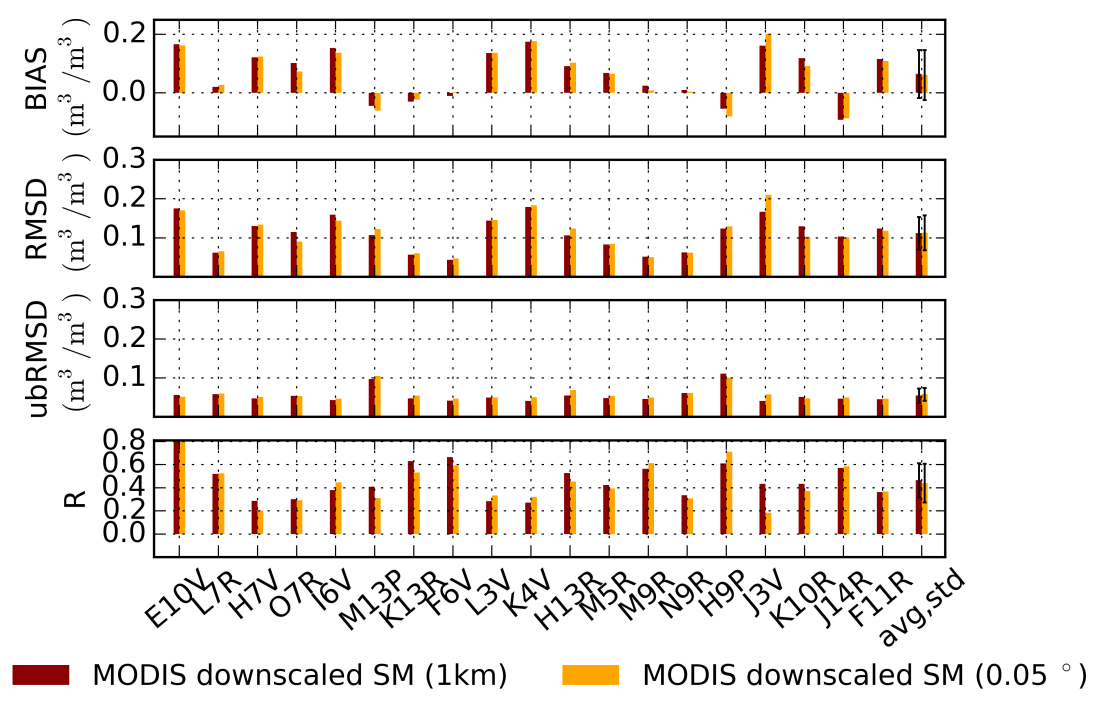

Figure 12. Bar plots for the comparisons between measured soil moisture and downscaled soil moisture at $1 \mathrm{~km}$ and $0.05^{\circ}$ spatial resolutions.

gests that finer spatial resolution data sets can improve the accuracy of downscaled soil moisture, which demonstrates the assumption proposed by Sánchez-Ruiz et al. (2014). In summary, the above results indicate that the downscaling scheme can be applied at different spatial resolutions. Taking advantage of the high spatial resolution of MODIS data sets, the combined use of MODIS and MSG data sets has the potential of providing downscaled soil moisture at high spatial and temporal resolutions.

\section{Conclusions}

In this study, a newly developed soil moisture downscaling method was applied to the ESA CCI soil moisture product and validated against the REMEDHUS soil moisture observation network in Spain. In general, agreement between the CCI soil moisture and the in situ soil moisture was observed with a similar accuracy level to the published validation studies. But systematic overestimation of soil moisture was also observed for CCI SM from the network-averaged analysis. Before applying the downscaling scheme, the sensitivity analyses of the downscaling factor VTCI were conducted. The surface temperature difference method performs better than instantaneous surface temperature method due to the integrated information of thermal inertial. Furthermore, the VTCI performance also depends on the type of vegetation index. The LAI performs best for the estimation of VTCI compared to NDVI, EVI, and FPAR. After downscaling the CCI soil moisture from coarse to high spatial resolution, the soil moisture map can replicate the CCI soil moisture spatial patterns and show more spatial details. Comparisons with in situ soil moisture indicate that the downscaled soil moisture can maintain the accuracy of original CCI soil moisture. Further inter-comparisons with published soil moisture downscaling studies suggest that the accuracy level of the proposed method is comparable. Compared with those methods, the advantages of the proposed method are its simplicity, the fewer required inputs, and comparable accuracy level.

In addition, the downscaled soil moisture from MSG SEVIRI performs better than that from MODIS, which is due 
to the better performance of corresponding VTCI from SEVIRI. It indicates the great potential of applying SEVIRI to downscale soil moisture. To take full advantages of the high temporal resolution of SEVIRI and high spatial resolution of MODIS, combined use of data from both platforms should be considered in soil moisture downscaling applications in the future.

In summary, the present study, together with the work by Peng et al. (2016), demonstrated the feasibility of downscaling soil moisture with the proposed method. The notable advantage of this approach is simplicity in terms of inputs requirement and implementation. Furthermore, the proposed method is independent on satellite platforms, implying that the downscaled soil moisture can be obtained at either very high spatial resolution ( $500 \mathrm{~m}$ for MODIS) or very high temporal resolution (every $15 \mathrm{~min}$ for SEVIRI). It has potential to facilitate regional hydrological related studies that require soil moisture information at different spatial and temporal scales. Application of the proposed method in other regions and comparison with other downscaling methods will be conducted in future studies.

Acknowledgements. The authors would like to thank the Level 1 and Atmosphere Archive and Distribution System (LAADS) and the Land Surface Analysis Satellite Applications Facility (LSA$\mathrm{SAF}$ ), as well as European Space Agency (ESA) for providing the satellite-based products. In addition, the authors would like to thank the International Soil Moisture Network (ISMN) for making the in situ measurements over REMEDHUS publicly available. The authors also would like to thank José Martínez-Fernández from Universidad de Salamanca for providing rainfall measurements from weather stations installed in the REMEDHUS observation network. In addition, the authors thank Fabio Cresto Aleina for reviewing a previous version of the manuscript. This research was supported by the Cluster of Excellence CliSAP (EXC177), University of Hamburg, funded through the German Science Foundation (DFG), the MPG-CAS postdoc fellowship, as well as the ESA CCI programme (CMUG).

The article processing charges for this open-access publication were covered by the Max Planck Society.

Edited by: W. Wagner

\section{References}

Albergel, C., de Rosnay, P., Gruhier, C., Muñoz-Sabater, J., Hasenauer, S., Isaksen, L., Kerr, Y., and Wagner, W.: Evaluation of remotely sensed and modelled soil moisture products using global ground-based in situ observations, Remote Sens. Environ., 118, 215-226, 2012.

Albergel, C., Dorigo, W., Reichle, R. H., Balsamo, G., de Rosnay, P., Muñoz-Sabater, J., Isaksen, L., de Jeu, R., and Wagner, W.: Skill and Global Trend Analysis of Soil Moisture from Reanalyses and Microwave Remote Sensing, J. Hydrometeorol., 14, 1259-1277, 2013.
Bárdossy, A. and Lehmann, W.: Spatial distribution of soil moisture in a small catchment. Part 1: geostatistical analysis, J. Hydrol., 206, 1-15, 1998.

Bastiaanssen, W. G., Molden, D. J., and Makin, I. W.: Remote sensing for irrigated agriculture: examples from research and possible applications, Agr. Water Manage., 46, 137-155, 2000.

Brocca, L., Hasenauer, S., Lacava, T., Melone, F., Moramarco, T., Wagner, W., Dorigo, W., Matgen, P., Martínez-Fernández, J., and Llorens, P.: Soil moisture estimation through ASCAT and AMSR-E sensors: An intercomparison and validation study across Europe, Remote Sens. Environ., 115, 3390-3408, 2011.

Carlson, T. N., Perry, E. M., and Schmugge, T. J.: Remote estimation of soil moisture availability and fractional vegetation cover for agricultural fields, Agr. Forest Meteorol., 52, 45-69, 1990.

Carlson, T. N., Gillies, R. R., and Perry, E. M.: A method to make use of thermal infrared temperature and NDVI measurements to infer surface soil water content and fractional vegetation cover, Remote Sens. Rev., 9, 161-173, 1994.

Castro, J., Zamora, R., Hódar, J. A., and Gómez, J. M.: Seedling establishment of a boreal tree species (Pinus sylvestris) at its southernmost distribution limit: consequences of being in a marginal Mediterranean habitat, J. Ecol., 92, 266-277, 2004.

Ceballos, A., Martínez-Fernández, J., and Luengo-Ugidos, M. Á.: Analysis of rainfall trends and dry periods on a pluviometric gradient representative of Mediterranean climate in the Duero Basin, Spain, J. Arid Environ., 58, 215-233, 2004.

Ceballos, A., Scipal, K., Wagner, W., and Martínez-Fernández, J.: Validation of ERS scatterometer derived soil moisture data in the central part of the Duero Basin, Spain, Hydrol. Process., 19, 1549-1566, 2005.

Chauhan, N. S., Miller, S., and Ardanuy, P.: Spaceborne soil moisture estimation at high resolution: a microwave-optical/IR synergistic approach, Int. J. Remote Sens., 24, 4599-4622, 2003.

Choi, M. and Hur, Y.: A microwave-optical/infrared disaggregation for improving spatial representation of soil moisture using AMSR-E and MODIS products, Remote Sens. Environ., 124, 259-269, 2012.

Coll, C., Wan, Z., and Galve, J. M.: Temperature-based and radiance-based validations of the V5 MODIS land surface temperature product, J. Geophys. Res.-Atmos., 114, D20102, doi:10.1029/2009JD012038, 2009.

Crow, W. T., Wood, E. F., and Dubayah, R.: Potential for downscaling soil moisture maps derived from spaceborne imaging radar data, J. Geophys. Res.-Atmos., 105, 2203-2212, 2000.

de Tomás, A., Nieto, H., Guzinski, R., Salas, J., Sandholt, I., and Berliner, P.: Validation and scale dependencies of the triangle method for the evaporative fraction estimation over heterogeneous areas, Remote Sens. Environ., 152, 493-511, 2014.

Dorigo, W., de Jeu, R., Chung, D., Parinussa, R., Liu, Y., Wagner, W., and Fernández-Prieto, D.: Evaluating global trends (19882010) in harmonized multi-satellite surface soil moisture, Geophys. Res. Lett., 39, L18405, doi:10.1029/2012GL052988, 2012.

Dorigo, W. A., Wagner, W., Hohensinn, R., Hahn, S., Paulik, C., Xaver, A., Gruber, A., Drusch, M., Mecklenburg, S., van Oevelen, P., Robock, A., and Jackson, T.: The International Soil Moisture Network: a data hosting facility for global in situ soil moisture measurements, Hydrol. Earth Syst. Sci., 15, 1675-1698, doi:10.5194/hess-15-1675-2011, 2011. 
Dorigo, W. A., Xaver, A., Vreugdenhil, M., Gruber, A., Hegyiová, A., Sanchis-Dufau, A. D., Zamojski, D., Cordes, C., Wagner, W., and Drusch, M.: Global Automated Quality Control of In Situ Soil Moisture Data from the International Soil Moisture Network, Vadose Zone J., 12, 3, doi:10.2136/vzj2012.0097, 2013.

Dorigo, W. A., Gruber, A., De Jeu, R. A. M., Wagner, W., Stacke, T., Loew, A., Albergel, C., Brocca, L., Chung, D., Parinussa, R. M., and Kidd, R.: Evaluation of the ESA CCI soil moisture product using ground-based observations, Remote Sens. Environ., 162, 380-395, 2015.

Douville, H., Viterbo, P., Mahfouf, J.-F., and Beljaars, A. C. M.: Evaluation of the Optimum Interpolation and Nudging Techniques for Soil Moisture Analysis Using FIFE Data, Mon. Weather Rev., 128, 1733-1756, 2000.

Entekhabi, D., Reichle, R. H., Koster, R. D., and Crow, W. T.: Performance Metrics for Soil Moisture Retrievals and Application Requirements, J. Hydrometeorol., 11, 832-840, 2010.

Fang, B. and Lakshmi, V.: Soil moisture at watershed scale: Remote sensing techniques, J. Hydrol., 516, 258-272, 2014.

Fensholt, R., Sandholt, I., and Rasmussen, M. S.: Evaluation of MODIS LAI, fAPAR and the relation between fAPAR and NDVI in a semi-arid environment using in situ measurements, Remote Sens. Environ., 91, 490-507, 2004.

Fensholt, R., Anyamba, A., Stisen, S., Sandholt, I., Pak, E., and Small, J.: Comparisons of compositing period length for vegetation index data from polar-orbiting and geostationary satellites for the cloud-prone region of West Africa, Photogram. Eng. Remote Sens., 73, 297-309, 2007.

Gao, Z., Xu, X., Wang, J., Yang, H., Huang, W., and Feng, H.: A method of estimating soil moisture based on the linear decomposition of mixture pixels, Math. Comput. Model., 58, 606-613, 2013

Hain, C. R., Crow, W. T., Mecikalski, J. R., Anderson, M. C., and Holmes, T.: An intercomparison of available soil moisture estimates from thermal infrared and passive microwave remote sensing and land surface modeling, J. Geophys. Res.-Atmos., 116, D15107, doi:10.1029/2011JD015633, 2011.

Hollmann, R., Merchant, C. J., Saunders, R., Downy, C., Buchwitz, M., Cazenave, A., Chuvieco, E., Defourny, P., de Leeuw, G., Forsberg, R., Holzer-Popp, T., Paul, F., Sandven, S., Sathyendranath, S., van Roozendael, M., and Wagner, W.: The ESA Climate Change Initiative: Satellite Data Records for Essential Climate Variables, B. Am. Meteorol. Soc., 94, 1541-1552, 2013.

Huete, A., Didan, K., Miura, T., Rodriguez, E. P., Gao, X., and Ferreira, L. G.: Overview of the radiometric and biophysical performance of the MODIS vegetation indices, Remote Sens. Environ., 83, 195-213, 2002.

Jacquette, E., Al Bitar, A., Mialon, A., Kerr, Y., Quesney, A., Cabot, F., and Richaume, P.: SMOS CATDS level 3 global products over land, Proc. SPIE 7824, Remote Sens. Agr. Ecosyst. Hydrol., XII, 78240K, doi:10.1117/12.865093, 2010.

Karnieli, A., Agam, N., Pinker, R. T., Anderson, M., Imhoff, M. L., Gutman, G. G., Panov, N., and Goldberg, A.: Use of NDVI and land surface temperature for drought assessment: merits and limitations, J. Climate, 23, 618-633, 2010.

Kerr, Y. H., Waldteufel, P., Wigneron, J.-P., Martinuzzi, J.-M., Font, J., and Berger, M.: Soil moisture retrieval from space: The Soil Moisture and Ocean Salinity (SMOS) mission, IEEE T. Geosci. Remote, 39, 1729-1735, 2001.
Kim, J. and Hogue, T. S.: Improving spatial soil moisture representation through integration of AMSR-E and MODIS products, IEEE T. Geosci. Remote, 50, 446-460, 2012.

Liu, Y. Y., Parinussa, R. M., Dorigo, W. A., De Jeu, R. A. M., Wagner, W., van Dijk, A. I. J. M., McCabe, M. F., and Evans, J. P.: Developing an improved soil moisture dataset by blending passive and active microwave satellite-based retrievals, Hydrol. Earth Syst. Sci., 15, 425-436, doi:10.5194/hess-15-425-2011, 2011.

Liu, Y. Y., Dorigo, W. A., Parinussa, R. M., De Jeu, R. A. M., Wagner, W., McCabe, M. F., Evans, J. P., and Van Dijk, A. I. J. M.: Trend-preserving blending of passive and active microwave soil moisture retrievals, Remote Sens. Environ., 123, 280-297, 2012.

Lobell, D. B. and Asner, G. P.: Moisture Effects on Soil Reflectance, Soil Sci. Soc. Am. J., 66, 722-727, 2002.

Loew, A.: Impact of surface heterogeneity on surface soil moisture retrievals from passive microwave data at the regional scale: The Upper Danube case, Remote Sens. Environ., 112, 231-248, 2008.

Loew, A., Ludwig, R., and Mauser, W.: Derivation of surface soil moisture from ENVISAT ASAR wide swath and image mode data in agricultural areas, IEEE T. Geosci. Remote, 44, 889-899, 2006.

Loew, A., Stacke, T., Dorigo, W., de Jeu, R., and Hagemann, S.: Potential and limitations of multidecadal satellite soil moisture observations for selected climate model evaluation studies, Hydrol. Earth Syst. Sci., 17, 3523-3542, doi:10.5194/hess-17-35232013, 2013.

Long, D., Singh, V. P., and Scanlon, B. R.: Deriving theoretical boundaries to address scale dependencies of triangle models for evapotranspiration estimation, J. Geophys. Res.-Atmos., 117, D05113, doi:10.1029/2011JD017079, 2012.

Mallick, K., Bhattacharya, B. K., and Patel, N.: Estimating volumetric surface moisture content for cropped soils using a soil wetness index based on surface temperature and NDVI, Agr. Forest Meteorol., 149, 1327-1342, 2009.

Martínez-Fernández, J. and Ceballos, A.: Temporal Stability of Soil Moisture in a Large-Field Experiment in Spain, Soil Sci. Soc. Am. J., 67, 1647-1656, 2003.

Merlin, O., Al Bitar, A., Walker, J. P., and Kerr, Y.: A sequential model for disaggregating near-surface soil moisture observations using multi-resolution thermal sensors, Remote Sens. Environ., 113, 2275-2284, 2009.

Moran, M. S., Clarke, T. R., Inoue, Y., and Vidal, A.: Estimating crop water deficit using the relation between surface-air temperature and spectral vegetation index, Remote Sens. Environ., 49, 246-263, 1994.

Naeimi, V., Scipal, K., Bartalis, Z., Hasenauer, S., and Wagner, W.: An Improved Soil Moisture Retrieval Algorithm for ERS and METOP Scatterometer Observations, IEEE T. Geosci. Remote, 47, 1999-2013, 2009.

Nemani, R., Hashimoto, H., Votava, P., Melton, F., Wang, W., Michaelis, A., Mutch, L., Milesi, C., Hiatt, S., and White, M. Monitoring and forecasting ecosystem dynamics using the Terrestrial Observation and Prediction System (TOPS), Remote Sens. Environ., 113, 1497-1509, 2009.

Njoku, E. G., Jackson, T. J., Lakshmi, V., Chan, T. K., and Nghiem, S. V.: Soil moisture retrieval from AMSR-E, IEEE T. Geosci. Remote, 41, 215-229, 2003. 
Owe, M., de Jeu, R., and Holmes, T.: Multisensor historical climatology of satellite-derived global land surface moisture, J. Geophys. Res.-Earth, 113, F01002, doi:10.1029/2007JF000769, 2008.

Parinussa, R. M., Holmes, T. R. H., Wanders, N., Dorigo, W. A., and de Jeu, R. A. M.: A Preliminary Study toward Consistent Soil Moisture from AMSR2, J. Hydrometeorol., 16, 932-947, 2014a.

Parinussa, R. M., Yilmaz, M. T., Anderson, M. C., Hain, C. R., and de Jeu, R. A. M.: An intercomparison of remotely sensed soil moisture products at various spatial scales over the Iberian Peninsula, Hydrol. Process., 28, 4865-4876, 2014b.

Patel, N. R., Anapashsha, R., Kumar, S., Saha, S. K., and Dadhwal, V. K.: Assessing potential of MODIS derived temperature/vegetation condition index (TVDI) to infer soil moisture status, Int. J. Remote Sens., 30, 23-39, 2008.

Peng, J. and Loew, A.: Evaluation of Daytime Evaporative Fraction from MODIS TOA Radiances Using FLUXNET Observations, Remote Sens., 6, 5959-5975, 2014.

Peng, J., Liu, Y., and Loew, A.: Uncertainties in Estimating Normalized Difference Temperature Index From TOA Radiances, IEEE T. Geosci. Remote, 51, 2487-2497, 2013a.

Peng, J., Liu, Y., Zhao, X., and Loew, A.: Estimation of evapotranspiration from MODIS TOA radiances in the Poyang Lake basin, China, Hydrol. Earth Syst. Sci., 17, 1431-1444, doi:10.5194/hess-17-1431-2013, 2013b.

Peng, J., Niesel, J., Loew, A., Zhang, S., and Wang, J.: Evaluation of Satellite and Reanalysis Soil Moisture Products over Southwest China Using Ground-Based Measurements, Remote Sensing, 7, 15729-15747, 2015.

Peng, J., Loew, A., Zhang, S., Wang, J., and Niesel, J.: Spatial Downscaling of Satellite Soil Moisture Data Using a Vegetation Temperature Condition Index, IEEE T. Geosci. Remote, 54, 558566, 2016

Peres, L. F. and DaCamara, C. C.: Land surface temperature and emissivity estimation based on the two-temperature method: sensitivity analysis using simulated MSG/SEVIRI data, Remote Sens. Environ., 91, 377-389, 2004.

Petropoulos, G., Carlson, T., Wooster, M., and Islam, S.: A review of Ts/VI remote sensing based methods for the retrieval of land surface energy fluxes and soil surface moisture, Prog. Phys. Geogr., 33, 224-250, 2009.

Petropoulos, G. P., Ireland, G., and Barrett, B.: Surface soil moisture retrievals from remote sensing: Current status, products $\&$ future trends, Phys. Chem. Earth Pt. A/B/C, 83-84, 36-56, doi:10.1016/j.pce.2015.02.009, 2015.

Piles, M., Camps, A., Vall-Llossera, M., Corbella, I., Panciera, R., Rüdiger, C., Kerr, Y. H., and Walker, J.: Downscaling SMOSDerived Soil Moisture Using MODIS Visible/Infrared Data, IEEE T. Geosci. Remote, 49, 3156-3166, 2011.

Piles, M., Sánchez, N., Vall-llossera, M., Camps, A., MartínezFernández, J., Martínez, J., and Gonzáez-Gambau, V. n.: A downscaling approach for SMOS land observations: evaluation of high-resolution soil moisture maps over the Iberian Peninsula, IEEE J. Select. Top. Appl. Earth Obs. Rem. Sens., 7, 3845-3857, 2014.

Porporato, A., Daly, E., and Rodriguez-Iturbe, I.: Soil water balance and ecosystem response to climate change, Am. Nat., 164, 625632,2004
Qin, J., Yang, K., Lu, N., Chen, Y., Zhao, L., and Han, M.: Spatial upscaling of in-situ soil moisture measurements based on MODIS-derived apparent thermal inertia, Remote Sens. Environ., 138, 1-9, 2013.

Qiu, Y., Fu, B., Wang, J., and Chen, L.: Spatial variability of soil moisture content and its relation to environmental indices in a semi-arid gully catchment of the Loess Plateau, China, J. Arid Environ., 49, 723-750, 2001.

Reichstein, M., Rey, A., Freibauer, A., Tenhunen, J., Valentini, R., Banza, J., Casals, P., Cheng, Y., Grünzweig, J. M., and Irvine, J.: Modeling temporal and large-scale spatial variability of soil respiration from soil water availability, temperature and vegetation productivity indices, Global Biogeochem. Cy., 17, 1104, doi:10.1029/2003GB002035, 2003.

Sahoo, A. K., De Lannoy, G. J., Reichle, R. H., and Houser, P. R.: Assimilation and downscaling of satellite observed soil moisture over the Little River Experimental Watershed in Georgia, USA, Adv. Water Resour., 52, 19-33, 2013.

Salomonson, V. V., Barnes, W., Maymon, P. W., Montgomery, H. E., and Ostrow, H.: MODIS: advanced facility instrument for studies of the Earth as a system, IEEE T. Geosci. Remote, 27, 145-153, 1989.

Sánchez, N., Martínez-Fernández, J., Calera, A., Torres, E., and Pérez-Gutiérrez, C.: Combining remote sensing and in situ soil moisture data for the application and validation of a distributed water balance model (HIDROMORE), Agr. Water Manage., 98, 69-78, 2010.

Sánchez, N., Martínez-Fernández, J., Scaini, A., and PérezGutierrez, C.: Validation of the SMOS 2 soil moisture data in the REMEDHUS network (Spain), IEEE T. Geosci. Remote, 50, 1602-1611, 2012.

Sánchez-Ruiz, S., Piles, M., Sánchez, N., Martínez-Fernández, J., Vall-llossera, M., and Camps, A.: Combining SMOS with visible and near/shortwave/thermal infrared satellite data for high resolution soil moisture estimates, J. Hydrol., 516, 273-283, 2014.

Sandholt, I., Rasmussen, K., and Andersen, J.: A simple interpretation of the surface temperature/vegetation index space for assessment of surface moisture status, Remote Sens. Environ., 79, 213-224, 2002.

Schmetz, J., Pili, P., Tjemkes, S., Just, D., Kerkmann, J., Rota, S., and Ratier, A.: An Introduction to Meteosat Second Generation (MSG), B. Am. Meteorol. Soc., 83, 977-992, 2002.

Seneviratne, S. I., Corti, T., Davin, E. L., Hirschi, M., Jaeger, E. B., Lehner, I., Orlowsky, B., and Teuling, A. J.: Investigating soil moisture-climate interactions in a changing climate: A review, Earth-Sci. Rev., 99, 125-161, 2010.

Shu, Y., Stisen, S., Jensen, K. H., and Sandholt, I.: Estimation of regional evapotranspiration over the North China Plain using geostationary satellite data, Int. J. Appl. Earth Obs. Geoinf., 13, 192206, 2011.

Sobrino, J., Franch, B., Mattar, C., Jiménez-Muñoz, J., and Corbari, C.: A method to estimate soil moisture from Airborne Hyperspectral Scanner (AHS) and ASTER data: Application to SEN2FLEX and SEN3EXP campaigns, Remote Sens. Environ., 117, 415-428, 2012.

Srivastava, P., Han, D., Ramirez, M., and Islam, T.: Machine Learning Techniques for Downscaling SMOS Satellite Soil Moisture Using MODIS Land Surface Temperature for Hydrological Application, Water Resour. Manage., 27, 3127-3144, 2013. 
Stisen, S., Sandholt, I., Nørgaard, A., Fensholt, R., and Jensen, K. H.: Combining the triangle method with thermal inertia to estimate regional evapotranspiration - Applied to MSG-SEVIRI data in the Senegal River basin, Remote Sens. Environ., 112, 1242-1255, 2008.

Tang, R., Li, Z.-L., and Tang, B.: An application of the Ts-VI triangle method with enhanced edges determination for evapotranspiration estimation from MODIS data in arid and semi-arid regions: Implementation and validation, Remote Sens. Environ., 114, 540-551, 2010.

Tian, Y., Woodcock, C. E., Wang, Y., Privette, J. L., Shabanov, N. V., Zhou, L., Zhang, Y., Buermann, W., Dong, J., and Veikkanen, B.: Multiscale analysis and validation of the MODIS LAI product: I. Uncertainty assessment, Remote Sens. Environ., 83, 414-430, 2002.

Vereecken, H., Huisman, J., Pachepsky, Y., Montzka, C., Van Der Kruk, J., Bogena, H., Weihermüller, L., Herbst, M., Martinez, G., and Vanderborght, J.: On the spatio-temporal dynamics of soil moisture at the field scale, J. Hydrol., 516, 76-96, 2014.

Verstraeten, W. W., Veroustraete, F., van der Sande, C. J., Grootaers, I., and Feyen, J.: Soil moisture retrieval using thermal inertia, determined with visible and thermal spaceborne data, validated for European forests, Remote Sens.f Environ., 101, 299-314, 2006.

Wagner, W., Lemoine, G., and Rott, H.: A Method for Estimating Soil Moisture from ERS Scatterometer and Soil Data, Remote Sens. Environ., 70, 191-207, 1999.

Wagner, W., Pathe, C., Doubkova, M., Sabel, D., Bartsch, A., Hasenauer, S., Blöschl, G., Scipal, K., Martínez-Fernández, J., and Löw, A.: Temporal stability of soil moisture and radar backscatter observed by the Advanced Synthetic Aperture Radar (ASAR), Sensors, 8, 1174-1197, 2008.
Wagner, W., Dorigo, W., de Jeu, R., Fernandez, D., Benveniste, J., Haas, E., and Ertl, M.: Fusion of Active and Passive Microwave Observations to Create an Essential Climate Variable Data Record on Soil Moisture, ISPRS Annals of the Photogrammetry, Remote Sens. Spat. Inf. Sci., I-7, 315-321, 2012.

Wan, Z., Wang, P., and Li, X.: Using MODIS land surface temperature and normalized difference vegetation index products for monitoring drought in the southern Great Plains, USA, Int. J. Remote Sens., 25, 61-72, 2004.

Wang, K., Li, Z., and Cribb, M.: Estimation of evaporative fraction from a combination of day and night land surface temperatures and NDVI: A new method to determine the Priestley-Taylor parameter, Remote Sens. Environ., 102, 293-305, 2006.

Zeng, J., Li, Z., Chen, Q., Bi, H., Qiu, J., and Zou, P.: Evaluation of remotely sensed and reanalysis soil moisture products over the Tibetan Plateau using in-situ observations, Remote Sens. Environ., 163, 91-110, 2015.

Zhang, D., Tang, R., Zhao, W., Tang, B., Wu, H., Shao, K., and Li, Z.-L.: Surface Soil Water Content Estimation from Thermal Remote Sensing based on the Temporal Variation of Land Surface Temperature, Remote Sensing, 6, 3170-3187, 2014.

Zhao, W. and Li, A.: A Downscaling method for improving the spatial resolution of AMSR-E derived soil moisture product based on MSG-SEVIRI data, Remote Sensing, 5, 6790-6811, 2013. 